bioRxiv preprint doi: https://doi.org/10.1101/046094; this version posted June 13, 2017 . The copyright holder for this preprint (which was not certified by peer review) is the author/funder, who has granted bioRxiv a license to display the preprint in perpetuity. It is made available under aCC-BY-NC-ND 4.0 International license.

Syndecan and Wnt Axon Termination

\title{
Syndecan functions to regulate Wnt-dependent axon guidance in C. elegans
}

Samantha N. Hartin, Meagan Kurland and Brian D. Ackley

Department of Molecular Biosciences, University of Kansas, Lawrence, KS, 66045

1 I P a g e 
bioRxiv preprint doi: https://doi.org/10.1101/046094; this version posted June 13, 2017 . The copyright holder for this preprint (which was not certified by peer review) is the author/funder, who has granted bioRxiv a license to display the preprint in perpetuity. It is made available under aCC-BY-NC-ND 4.0 International license.

Syndecan and Wnt Axon Termination

Running title: Syndecan and Wnt Axon Termination

Keywords: Syndecan, Wnt Signaling, HSPGs, Hox Genes, $\beta$-catenin

Corresponding Author:

Brian D. Ackley

5004 Haworth Hall

1200 Sunnyside Ave

Lawrence, KS 66045

bdackley@ku.edu

8 Figures, 8 Tables, 1 Supplemental Figure

52 Pages

Abstract: 196 Words

Introduction: 497 Words

Results: 5807 Words

Discussion: 1913 Words

2 | P a g e 
Syndecan and Wnt Axon Termination

\begin{abstract}
Cell adhesion molecules are key to axon guidance during development, for example specific cues can instruct axons to terminate in a specific area, or to continue growth. Syndecans are conserved cellsurface receptors that function in multiple developmental contexts. Caenorhabditis elegans with mutations in the single syndecan gene, $s d n-1$, exhibited errors in anterior-posterior guidance, with axons that stopped short of, or grew past their stereotypical termination point. Syndecan function was cell non-autonomous for GABAergic axon outgrowth during early development, but was likely cell autonomous to inhibit growth later in development. $s d n-1$ appeared to regulate the inhibitory activity of the egl-20/Wnt ligand. Removing egl-20 from sdn-1 mutants resulted in fewer animals with prematurely terminating axons. The proteoglycan modifying enzymes $h s e-5$ and $h s t-2$, but not $h s t-6$, had similar effects, suggesting specific heparan sulfate modifications regulated EGL-20 axon-terminating activity. sdn-1 functioned with lin-17/Frizzled, bar-1/ $\beta$-catenin and the egl-5 Hox-like transcription factor in EGL-20-depedent axon outgrowth. bar-1 was required for egl-5 expression in the most posterior GABAergic neurons. sdn-1 mutations did not eliminate egl-5 expression, but over-expression of egl-5 rescued sdn-1 phenotypes. Our results suggest syndecan is a component of Wnt-signaling events that are necessary for axons to recognize appropriate termination points.
\end{abstract}


Syndecan and Wnt Axon Termination

\section{Introduction}

Nervous system development is an ordered and complex process that relies on axons interpreting multiple molecular cues to form functional circuits. Cues in the extracellular matrix (ECM) are essential to neurons forming appropriate networks. For example, ephrins and their receptors, EphRTKs, are key mediators of precise axon pathfinding in retino-tectal mapping (DRESCHER et al. 1997; THAKAR et al. 2011). Also, some guidance cues, for example Netrins, can serve as both attractants and repellants, depending on other extracellular factors, or the receptors present on the cell surface (KENNEDY et al. 1994; Colamarino And TeSsier-LAVIgne 1995; Chan et al. 1996; Wadsworth ANd Hedgecock 1996). Our complete understanding of how guidance cues orchestrate neural development remains incomplete. To that end, Caenorhabditis elegans provides a valuable model to study nervous system development. Growth and termination of the GABAergic motorneurons have identified novel axon guidance factors and/or new roles for known guidance cues (WIGHTMAN et al. 1997; HOBERT et al. 1999; HUANG et al. 2002; HUANG et al. 2003; Huarcaya Najarro And Ackley 2013; Opperman ANd Grill 2014).

Heparan sulfate proteoglycans and chondroitin sulfate proteoglycans (HSPGs and CSPGs, respectively) are crucial for proper axon guidance (YAMAGUCHI 2001; LEE AND CHIEN 2004; RAWSON et al. 2005; RHINER et al. 2005; Bulow et al. 2008; DiAZ-BALZAC et al. 2014; SHEN 2014). HS- and CSPG side chains are enzymatically modified to alter function (BULOW AND HOBERT 2004; WANG et al. 2015). For example, modified HS- or CS-side chains regulate the binding affinity and avidity for multiple signaling molecules including Wnts, FGFs and BMPs. As a functional consequence, HSPGs and CSPGs can create growth factor reservoirs in the ECM or function as co-receptors on the cell surface (BAEG AND PERRIMON 2000; TUMOVA et 
Syndecan and Wnt Axon Termination

al. 2000; YAMAguchi 2001; Aricescu et al. 2002; INATANI et al. 2003; SteIgemAnN et al. 2004; BiShOp et al. 2007).

Syndecans are a major family of HSPGs. Most mammalian genomes encode for four syndecan proteins, while the $C$. elegans genome encodes one, named $s d n-1$. SDN-1 functions autonomously in the

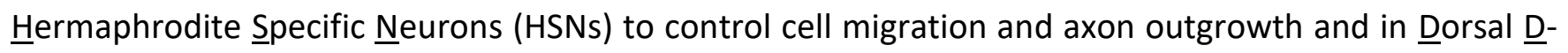
type and $\underline{V}$ entral $\underline{D}$-type motorneurons (DDs and VDs, respectively) to guide commissure growth along the dorsal-ventral axis (RHINER et al. 2005). SDN-1 regulates the guidance of non-neural tissues including the distal tip cells (DTC) that migrate along the anterior-posterior axis to shape the gonads during development.

Syndecan has been implicated in Wnt signaling in vertebrates and invertebrates alike (ALEXANDER et al. 2000; SCHWABIUK et al. 2009; DEJIMA et al. 2014). In C. elegans DTC guidance by SDN-1 interacts with the Wnt ligand, EGL-20. In early embryogenesis SDN-1 functions in a MOM-2/Wnt-dependent event to direct cell specification (DEJIMA et al. 2014). We have previously demonstrated that SDN-1 and LIN-44 function in genetically-redundant pathways during gastrulation (HARTIN et al. 2015). Together, these indicate SDN-1 functions in multiple Wnt growth factor signaling events. Here we expand those results by analyzing the interaction of SDN-1 and Wnt signaling in the control of axon termination. 
Syndecan and Wnt Axon Termination

\section{Materials and Methods}

\section{Strains and Genetics}

N2 (var. Bristol) was used as the wild-type reference strain in all experiments. Strains were maintained at $18-22{ }^{\circ} \mathrm{C}$, using standard maintenance techniques as described (BRENNER 1974). Alleles used in this report include: LGI, lin-44(n1792), lin-17(n671); LGII, mig-5(rh94); LGIII, egI-5(n945); LGIV, egl-20(lq42), egl-20(gk453010); LGV, mom-2(or77); LGX bar-1(ga80), sdn-1(ok449), sdn-1(zh20), hse5(tm472), hse-5(lq49), hst-2(ok595), hst-6(ok273). The following integrated transgenic lines were used: Ihls47 [Punc-25::mCherry], juls76 [Punc-25::gfp], oxls12 [Punc-47::gfp], muls32 [Pmec-7::gfp], juSi119 [Psdn-1::SDN-1CDNA::GFP::sdn-1 3'UTR] (DEJIMA et al. 2014), wpSi12 [Psdn-1::SDN-1::sdn-1 3'UTR] (Edwards And HammarLund 2014), lqls80 [Pscm::gfp], wpls54 [Pegl-5::EGL-5::GFP-3xFLAG] (NIU et al. 2011), and Ih/s93 [Punc-25::egl-5]. The following transgenic extrachromosomal arrays were used: IhEx435 [Punc-25::mCherry - $5 \mathrm{ng} / \mu \mathrm{l}] ;$ IhEx457 [Plin-17::lin-17::rfp - 2 ng/ $\mu$ l]; IhEx350, IhEx353, [Pegl-

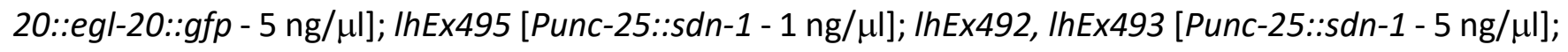

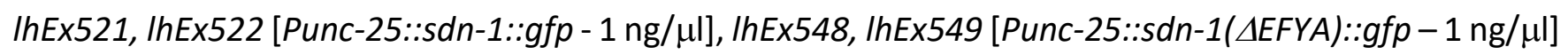
and IhEx601, IhEx602 [Punc-25::mCherry::mig-5::unc-43 3 'UTR - 2 ng/ $\mu \mathrm{l}]$.

\section{Plasmid Construction}

A sdn-1 cDNA was obtained from a cDNA library, initially transcribed by random hexamers and Superscript III (Life Technologies). The primers used to amplify the cDNA were as follows: sdn-1cDNAF1 5' caggtgattacaccaacaagac $-3^{\prime}$ and $s d n-1 c D N A R 15^{\prime}$ - cagataagtgccatcagaaacc - 3'. The resulting PCR product was cloned into the pCR8/GW/Topo entry vector (Life Technologies) to make pEVL424, and then recombined into the 
Punc-25 destination vector (pBA153) using LR recombinase (Life Technologies) per the manufacterer's protocol to generate pEVL449 (Punc-25::sdn-1). To generate pEVL454 (Punc-25::sdn-1::gfp) we cut pEVL424 with BstBI, and ligated with the gfp cassette from pPD113.37 (a gift of A. Fire) with Clal. Any additional cloning details are fully available upon request. The egl-5 genomic locus was amplified from wild-type genomic DNA using the following primers: egl-5F1 5' - ttggaaagcagtgagagtgag $-3^{\prime}$ and egl-5R1 5' - ggagggatcattgagaaacttgag $-3^{\prime}$. The PCR product was TOPO cloned intp pCR8/GW/TOPO to create pEVL483 and recombined into pBA153 by L/R clonase to make pEVL479 (Punc-25::egl-5). A mig-5 cDNA was amplified from a random cDNA library, using the following primers $5^{\prime}$ - caagcaccagtatctgcattatggagccgccatgca $-3^{\prime}$ and $5^{\prime}-$ agaaggttcttctagcccttcgcgttctgctgttg $-3^{\prime}$ and inserted via the NEBuilder (NEB) enzymatic mixture into pEVL387 [Punc-25::mCherry::unc-43 3'UTR], digested with Xbal. The underlined sequences above supply the overlap with the pEVL387 vector.

\section{Fluorescence microscopy}

Axon termination (GABAergic neurons) was visualized using juls76, oxls12, Ih/s47 or IhEx435 or (mechanosensory neurons) muls32. Scoring and imaging were done using an Olympus FV1000 laserscanning confocal microscope with the Fluoview software. Animals where the DNC bundle did not grow to the posterior edge the cell bodies located on the VNC, were considered under-extended. Animals in which the DNC axons grew past the cell bodies located on the VNC, were scored as over-extended. In cases where the VD motorneuron cell bodies were displaced the position of the anus was used as a secondary landmark. Animals with posterior neurites (Pdns) or other obvious axon guidance errors during commissural growth were not included in the analysis of DNC termination points. 
bioRxiv preprint doi: https://doi.org/10.1101/046094 this version posted June 13, 2017 . The copyright holder for this preprint (which was not certified by peer review) is the author/funder, who has granted bioRxiv a license to display the preprint in perpetuity. It is made available under aCC-BY-NC-ND 4.0 International license.

Syndecan and Wnt Axon Termination

\section{Statistics}

Fisher's exact test was used to evaluate the statistical significance between genotype pairs. P values were calculated with Prism GraphPad (5.0) program or the GraphPad QuickCalcs (http://www.graphpad.com/quickcalcs/). A multiple test correction (Bonferroni) was applied when used to evaluate relationships within groups of genotypes, relative to the number of comparisons being made within that experimental design.

\section{Data Availability}

All strains and plasmids presented are available upon request. 
Syndecan and Wnt Axon Termination

\section{Results}

\section{Syndecan is an anterior/posterior axon guidance factor}

The GABAergic D-type motorneurons cell bodies are located along the ventral nerve cord (VNC). The six Dorsal D-type (DD) and thirteen Ventral D-type (VD) cell bodies extend a single neuronal process anteriorly. The axon stalls, and initiates a dorsal commissural process and then a second process initiates from the stall point and extends a second anterior branch to the next most anterior VD neuron (Figure 1) (HuARCAYA NAJARRo AND ACKLEY 2013). The commissural process, upon reaching the dorsal nerve cord (DNC), bifurcates and sends processes both anteriorly and posteriorly. In the VNC and DNC, the VD processes fasciculate with those of the DD neurons and terminate at stereotyped positions along the anteroposterior axis (WHITE et al. 1986). The most posterior DD and VD processes extend as a bundle that terminates at the anteroposterior position superior to the locations of the DD6 and VD13 cell bodies, which are located on the ventral side (MARO et al. 2009) (Figure $1 \mathrm{~A}$ and B). The stereotyped development allows for detection of mutants with aberrant axon patterning phenotypes.

We observed that $s d n-1(z h 20)$ mutants had defects in formation of the GABAergic motorneurons along the anterior-posterior (A-P) axis of the animal. Animals with mutations in sdn-1 exhibited posteriorly-directed neurites (Pdns) (16\% 17$)$, where an axonal process was inappropriately projected toward the posterior of the animal (Huarcaya Najarro and Ackley, 2013). In animals where the axon projected normally toward the anterior we also observed defects where axons terminated along the A$\mathrm{P}$ axis in the dorsal nerve cord (Figure 1). We found that $35 \% \pm 13$ of $s d n-1(z h 20)$ mutants had axons that stopped short of the stereotyped termination point, while $26 \% \pm 10$ had axons that extended posteriorly past the proper termination point (Figure $1 \mathrm{D}-\mathrm{F}$, Table 1). It is worth noting that in other genetic contexts 
Syndecan and Wnt Axon Termination

where D-axon termination has been investigated it is common to observe both under- and overextension defects in the same genotypes (MARO et al. 2009; OPPERMAN AND GRILL 2014).

We also tested a second LOF allele, sdn-1(ok449) which results in an in-frame deletion that produces a shortened form of SDN-1. This shortened form lacks two of the major conserved heparan sulfate attachment sites in the extracellular domain (MINNITI et al. 2004). We found that animals with the ok449 mutation had similar defects to those found with the zh20 allele (Table 1). We continued our studies using the zh20 allele since it has been demonstrated to be a genetic and molecular null (Rhiner et al., 2005, Dejima et al., 2014).

The VD neurons are formed at the end of the first larval stage (L1), and finish their initial outgrowth during the beginning of the second larval stage (L2). We initially scored animals in the fourth larval stage (L4). Between the L2 and L4 stages the animals approximately double in length. During development, the posterior segment of the DNC (from the point of the final commissural branch to the terminus) increases from $\sim 25-30 \mu \mathrm{m}(\mathrm{L} 2)$ to $\sim 30-40 \mu \mathrm{m}(\mathrm{L} 4)$, and continues growing to $\sim 50-60 \mu \mathrm{m}$ in wild-type young adults. To determine if $s d n-1$ axon outgrowth errors were due to developmental errors or a failure to keep up with the growth of the animal we scored DNC termination in zh20 animals at the L2 stage. We found that like those scored at later stages, zh20 animals at the L2 stage had both under- (52\%) and over- (27\%) extended GABAergic axons in the DNC. We concluded from this analysis that, during initial formation, axons terminated growth aberrantly in most animals lacking sdn-1.

To determine if the effects of axon termination along the anterior-posterior axis were limited to the D-type neurons we examined the axons of the six mechanosensory neurons using an integrated GFP reporter, muls32. In wild-type animals the $\underline{A}$ terior Lateral Mechanosensory (ALMs) and the Posterior 
Syndecan and Wnt Axon Termination

Lateral Mechanosensory (PLMs) neurons extend anteriorly-directed axons from their cell bodies and have a characteristic termination point, with the PLMs terminating just posterior to the ALM cell bodies (Figure 1) and the ALMs terminating just posterior to the nose of the animal. In addition, ALM and PLM axons form largely parallel to the dorsal and/or ventral nerve cords, and do not appear to deviate in the dorsal-ventral axis, except where they make branches into the ventral nerve cord (PLMs) or the nerve ring (ALMs).

When we examined the ALM and PLM neurons in sdn-1(zh20) mutant animals we found disruptions in the outgrowth of the neurons. As had been previously reported the ALM cell bodies were frequently displaced posteriorly, likely due to incomplete cell migration (RHINER et al. 2005). Because of migration defects, we did not score axon termination errors in the ALMs. The PLM neurons do not undergo long range cell migrations, and were in grossly normal positions in zh20 mutants. We found PLM axons that were shortened in zh20 animals $(14 \% \pm 4, N=207)$, either by terminating prematurely or not elongating sufficiently during organismal growth. We also found instances where PLMs were over-extended, and could "hook" toward the ventral nerve cord (17\% \pm 6 ) (Figure 1) (GRILL et al. 2007). Overall these defects were less penetrant than those we observed in the DD/VD motorneurons, but were consistent with a role for $s d n-1$ in regulating axon extension along the A/P axis, and that loss of $s d n-1$ can result in errors in the precision with which axons terminate in different neuron types.

\section{Syndecan function is required in multiple tissues to regulate D-type neuron outgrowth}

We partially rescued the outgrowth phenotypes in the D-type neurons in $s d n-1(z h 20)$ animals by reintroducing sdn-1 (Table 1). We obtained a Mos1-mediated single copy insertion (MosSCl), juSi119, in 
which a GFP-tagged version of SDN-1, under the regulation of sdn-1 endogenous promoter elements, had been inserted on the second chromosome (LG II) (DEJIMA et al. 2014). The zh20; juSi119 animals had fewer undergrown axons in the DNC (Table 1), but had a higher rate of DNC overgrowth $(59 \% \pm 4)$ than was observed in zh20 mutants. To determine if this was due to a detrimental effect of the GFP insertion we obtained a second $\mathrm{MosSCl}$, wpSi12, which is inserted in the same chromosomal position, but is not GFP tagged (EDWARDS AND HAMMARLUND 2014). We again observed rescue of the under-extension phenotype, but increased overgrowth (Table 1).

To test whether $s d n-1$ could be functioning cell-autonomously we drove expression of $s d n-1$ specifically in the GABAergic neurons using the unc-25 promoter $(1 \mathrm{ng} / \mu \mathrm{l})$. Cell-specifically expressed $s d n-1$ partially rescued the over-extension phenotype in zh20 mutants in two separate lines $(26 \%-z h 20$ vs. $11 \%, P=0.0035$ and $10 \%, P=0.005)$. In both transgenic lines the rate of under-extended axons was not significantly changed (35\% - zh20 vs. $37 \%, P=0.60$ and $33 \%, P=0.91)$. No obvious differences were found in lines generated at a higher concentration $(5 \mathrm{ng} / \mu \mathrm{l})$. We were still unable to rescue the under-extension defects ( $36 \%$ vs $34 \%, P=0.94)$ and there was not a robust increase in the efficiency of rescuing the overextension defects ( $11 \%$ vs. $8 \%, P>0.05)$. We also cell-specifically expressed an SDN-1::GFP chimera in the GABAergic motorneurons, and found that we could again rescue over-extension, but not underextension. These data suggest that the over-extension of axons in zh20 animals was due to, at least in part, the cell-autonomous loss of $s d n-1$, but the under-extension phenotype demonstrated a requirement for $s d n-1$ function in other tissues.

Syndecans have been shown to be linked to cytoplasmic effectors via their PDZ binding motif. To determine if the conserved, potential PDZ binding motif (EFYA) at the very C-terminus was required for 
SDN-1 function in the D-neurons, we deleted it from our SDN-1::GFP. We cell-specifically expressed the SDN-1::GFP( $\triangle E F Y A)$ in the GABAergic motorneurons, and found that, unlike the receptor with the intact EFYA motif, this version failed to rescue the over-extension phenotype in sdn-1(zh20) animals (Table 1). This suggests that, intracellularly, SDN-1 may link to effectors that are important for axon termination via the EFYA motif.

Table 1. GABAergic DNC termination defects in Syndecan mutants

\begin{tabular}{|c|c|c|c|c|c|c|}
\hline \multirow[t]{2}{*}{ 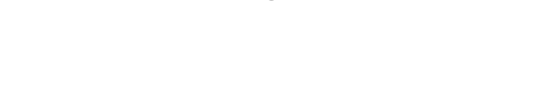 } & \multicolumn{4}{|c|}{$\%$ Observed (Mean \pm St. Dev) } & \multicolumn{2}{|c|}{ Comparison to $s d n-1(z h 20)$} \\
\hline & Under & WT & Over & $\mathrm{N}$ & $\mathrm{P}$ (under) & $\mathrm{P}$ (over) \\
\hline$s d n-1(z h 20)$ & $35 \pm 13$ & $39 \pm 10$ & $26 \pm 10$ & 246 & & \\
\hline sdn-1; juSi119 & $6 \pm 1$ & $36 \pm 3$ & $59 \pm 4$ & 200 & $<0.0001 \ddagger$ & $<0.0001 \ddagger$ \\
\hline sdn-1; wpSi12 & $1 \pm 1$ & $61 \pm 8$ & $38 \pm 9$ & 216 & $<0.0001 \ddagger$ & 0.0538 \\
\hline sdn-1; Punc-25::sdn-1 (A) & $37 \pm 13$ & $52 \pm 8$ & $11 \pm 6$ & 81 & 0.6038 & $0.0035 \ddagger$ \\
\hline sdn-1; Punc-25::sdn-1 (B) & $33 \pm 3$ & $57 \pm 6$ & $10 \pm 3$ & 141 & 1 & 0.005 \\
\hline sdn-1; Punc-25::sdn-1::gfp & $33 \pm 4$ & $67 \pm 4$ & $0 \pm 0$ & 104 & 1 & $<0.0001 \ddagger$ \\
\hline sdn-1; Punc-25::sdn-1(AEFYA)::gfp & $30 \pm 6$ & $43 \pm 1$ & $28 \pm 5$ & 159 & 0.3844 & 0.4155 \\
\hline
\end{tabular}

\section{Syndecan is enriched in the DNC near the VD13 termination point}

We examined the localization of SDN-1GFP expressed by juSi119. The protein was present broadly throughout the animal. We observed robust expression in the DNC and tissues surrounding it, including the muscle, epidermis and intestinal cells (Figure 2). We further examined whether SDN-1 was expressed in the D-type neurons using a cytoplasmic RFP (Punc-25::mCherry). We found that, while SDN-1GFP was present in the ventral and dorsal nerve cords, we were unable to detect robust expression in the D-type neurons. We examined animals specifically when the VD13 commissure was being formed, and found no detectable SDN-1::GFP in the growth cone (Figure 2). This was curious since previous work has suggested the $s d n-1$ promoter is active in the D-type neurons (Rhiner et al., 2005). Since we were unable to rescue the overgrowth phenotype with the MosSCl integrated transgenes, but we could with cell- 
Syndecan and Wnt Axon Termination

autonomous expression, we inferred the MosSCI integrated SDN-1 transgenes into LGII may have been poorly expressed in the GABAergic neurons.

While we did not detect abundant SDN-1::GFP in VD neurons, we did find that, in the DNC, SDN1::GFP was enriched near the normal termination point of the GABAergic neurons (Figure 2). In L1 animals, prior to the formation of the VD13 neuron, we found that SDN-1::GFP accumulated in the nervous system, and aggregated near the termination point of the GABAergic neurons in the DNC (Figure 2). This suggests that SDN-1::GFP would be in a position to assist the later arriving VD13 axon in identifying the proper termination point. When we examined the SDN-1::GFP after all the VD axons had formed (Figure 2) we found that SDN-1::GFP was maintained at the termination point of the VD13 axon, being present in L4 (Figure 2) and adult animals (not shown).

The Punc-25::SDN-1::GFP transgene was capable of rescuing the dorsal cord growth defects as efficiently as the non-tagged version (Table 1). In these animals, we observed SDN-1 in cell bodies and along the ventral, commissural and dorsal processes of the neurons (Figure 2), but no specific enrichment at the termination point of the DNC. From this analysis, we concluded that SDN-1 was localized such that it could make a local contribution to GABAergic axon termination in the dorsal nerve cord, and that, within the GABAergic neurons SDN-1 could localize to the dorsal cord. We also concluded that SDN-1 accumulation near the termination point of the dorsal nerve cord observed by juSi119 likely represented contributions from multiple tissue types.

We subsequently analyzed the localization of the SDN-1::GFP( $\triangle \mathrm{EFYA})$. Unlike the SDN-1::GFP, which appeared to localize evenly to the dorsal and ventral cords, the version of SDN-1 lacking the EFYA motif was biased towards accumulation in the ventral nerve cord, relative to the dorsal nerve cord 
Syndecan and Wnt Axon Termination

(Figure 2). We cannot differentiate whether this reflects a failure in trafficking or retention of the receptor in the dorsal aspect of the neuron. However, it is consistent with the EFYA motif being required for rescue in the D-type neurons.

\section{SDN-1 function is epistatic to LIN-44 in VD neurons, but not PLMs}

Previous work has demonstrated that Wnt signaling can regulate axon termination of the D-type neurons (MARo et al. 2009). Consistent with those observations we also found that animals with mutations in the most posteriorly expressed Wnt ligand, lin-44(n1792), caused the DNC axons to be overextended (Figure 3, Table 2). Previously we described that sdn-1 and lin-44 exhibit a synthetic lethal genetic interaction in early development, with $\sim 75 \%$ of double mutants dying during embryogenesis (HARTIN et al. 2015). To determine whether sdn-1 was functioning in lin-44 dependent outgrowth we scored the axons in the surviving animals. Unlike the lin-44 single mutants, the doubles exhibited both under and over-extended DNCs (Figure 3, Table 2). Qualitatively, we assessed the over-extended DNCs in the $s d n-1$; lin-44 mutants to be more like those of the lin-44 animals, as they extended further into the posterior than was typically seen in $s d n-1$ mutants. Thus, we concluded that $s d n-1$ loss of function was partially epistatic to axon overgrowth caused by lin-44. We hypothesized that the undergrown axons might terminate prior to reaching the position where they would be sensitive to the presence (or absence) of lin-44. However, axons that did extend past the normal termination point were affected by the loss of lin-44, and protruded into more posterior regions of the animal.

Mutations in lin-44 also affect the direction and extent of axon outgrowth of the PLM axons (HILLIARD AND BARGMANN 2006) (S. Figure 1). Loss of function in lin-44 resulted in PLMs with posteriorly directed 
Syndecan and Wnt Axon Termination

axons $(54 \% \pm 18, N=181)$ and altered lengths of posterior and anterior processes, including animals where the processes appeared to be of equal length $(20 \% \pm 15)$ and animals with longer anterior processes, but that stop short of the normal termination point ( $9 \% \pm 4)$. The surviving lin-44; sdn-1 animals had an increase in the number of reversed PLMs $(85 \% \pm 6, N=200 \mathrm{P}<0.0001$ vs lin-44 alone). Thus, we concluded that $s d n-1$ function was not epistatic to lin-44 in PLMs, rather, in parallel. And that sdn-1 had a similar, but weaker effect on PLM polarity as lin-44, but the effect was only obvious in the animals also lacking lin-44. To better understand how sdn-1 functioned in axon outgrowth we focused the remainder of our study on dorsal nerve cord termination in the D-type neurons.

\section{EGL-20 and LIN-44 function in parallel in GABAergic development}

A second Wnt ligand, egl-20, has also been found to affect GABAergic neuron termination in the DNC (MARo et al. 2009). We obtained two putative null alleles of egl-20, lq42 (JOSEPHSON et al. 2016) and gk453010 from the Million Mutation Project (THOMPSON et al. 2013). Both lq42 and gk453010 introduce premature stop codons in the egl-20 mRNA, unlike the reference allele, $n 585$, which is a missense mutation. We found that in both egl-20(Iq42) and egl-20(gk453010) axons over-extended into the posterior (Table 2). We subsequently used the gk453010 allele for future analyses. Qualitatively, we observed that the extent to which the axons extended past the expected termination point was shorter in egl-20 than in lin-44 mutants, which is consistent with their patterns of expression, with egl-20 being expressed in a region just anterior to the expression of lin-44.

We generated lin-44; egl-20 double mutants, and found that a higher number of animals than expected exhibited Pdn defects $(27 \% \pm 6$, compared to $0.5 \%$ - egl-20, and $1.5 \%$ - lin-44), as well as 
Syndecan and Wnt Axon Termination

additional guidance defects during commissural growth, making it difficult to accurately assess the DNC phenotype. In the axons that could be scored, we found that most of the animals had over-extended DNCs (Table 2). Qualitatively, as in the sdn-1; lin-44 doubles, the length of the over-extended DNCs appeared more severe in the Wnt double mutant than in $s d n-1$ single mutants, which is consistent with previous reports, using other alleles of egl-20 (MARO et al. 2009). We also generated lin-44; egl-20; sdn1 triple mutants, which were like the lin-44; egl-20 doubles, but exhibiting an even higher rate of Pdn defects (69 \pm 7$)$, axon guidance errors, as well as over- and under-extended DNCs.

These results suggest there are multiple Wnt-mediated events in the development of the GABAergic neurons where EGL-20 and LIN-44 were functioning. First, EGL-20 and LIN-44 functioned in a partially redundant fashion to instruct growth anteriorly from the cell body. Subsequently, EGL-20 and LIN-44 functioned in a partially overlapping manner to regulate guidance of the axons including the where the axons would terminate in the DNC.

Table 2. Wnt ligands and sdn-1 DNC termination phenotypes

\begin{tabular}{|c|c|c|c|c|c|c|c|}
\hline \multicolumn{4}{|c|}{$\%$ Observed (Mean \pm St. Dev) } & \multicolumn{2}{|c|}{ Comparison to single mutants } & \multirow[t]{2}{*}{ Pdn \% } & \multirow[t]{2}{*}{$\mathrm{N}$} \\
\hline Under & WT & Over & $\mathrm{N}$ & $\mathrm{P}$ (under) & $\mathrm{P}$ (over) & & \\
\hline $1 \pm 1$ & $8 \pm 3$ & $91 \pm 5$ & 197 & & & $2 \pm 2$ & 200 \\
\hline $27 \pm 6$ & $35 \pm 11$ & $38 \pm 10$ & 118 & $\begin{array}{c}0.2247 \\
<0.0001^{a}\end{array}$ & $\begin{array}{l}0.0026 \mp \\
<0.0001^{\text {a }}\end{array}$ & $16 \pm 1$ & 140 \\
\hline $0 \pm 0$ & 36 & 64 & 100 & & & $0 \pm 0$ & 100 \\
\hline $0 \pm 0$ & $29 \pm 4$ & $71 \pm 4$ & 176 & & & $1 \pm 1$ & 177 \\
\hline $15 \pm 4$ & $39 \pm 18$ & $45 \pm 15$ & 224 & $\begin{array}{l}<0.0001 \neq \\
<0.0001 \text { b }\end{array}$ & $\begin{array}{l}0.0007 \ddagger \\
<0.0001^{b}\end{array}$ & $22 \pm 16$ & 291 \\
\hline $1 \pm 1$ & $21 \pm 11$ & $78 \pm 12$ & 154 & $\begin{array}{c}1.000 \\
0.4693\end{array}$ & $\begin{array}{c}0.0073^{a} \\
0.0713\end{array}$ & $33 \pm 7$ & 225 \\
\hline & & & & Comparis & $n-44 ;$ egl-20 & & \\
\hline $15 \pm 12$ & $9 \pm 5$ & $76 \pm 7$ & 74 & $<0.0001^{c}$ & 0.4879 & $69 \pm 7$ & 236 \\
\hline
\end{tabular}

$\begin{array}{cc}\text { lin-44; egl-20; sdn-1 } & 15 \pm 12 \quad 9 \pm 5 \\ \text { \# Significantly different from sdn-1 }\end{array}$

a Significantly different from lin-44

${ }^{b}$ Significantly different from egl-20

c Significantly different from lin-44; egl-20 
Syndecan and Wnt Axon Termination

\section{SDN-1 inhibits EGL-20 axon repulsion during early DNC formation}

We next examined $s d n-1$; egl-20 double mutants. We found a reduction in the penetrance of the under-extension phenotype present in animals lacking both egl-20 and sdn-1 (Table 2). One interpretation of this was that, in sdn-1 mutants, EGL-20 was inducing premature termination of the DNC. Previous results have found that EGL-20 diffusion is regulated by SDN-1 (SCHWABIUK et al. 2009), and this would be consistent with EGL-20 exerting an inhibitory effect with a longer range of action when SDN-1 was absent. We tested this by expressing an EGL-20::GFP from its endogenous promoter. We found that D-type axons terminated near the site of EGL-20::GFP accumulation (Figure 4). Further, we found that over-expression of EGL-20 induced mild under-extension phenotypes in otherwise wild-type animals $(16 \% \pm 7)$. We crossed the transgenes into animals lacking $s d n-1$. The penetrance of underextension defects increased $(59 \% \pm 11)$, which was significantly higher than expected for animals simply lacking $s d n-1(\mathrm{P}<0.0001)$. These results indicate that over-expression of EGL-20 could induce premature termination of the GABAergic neurons in a syndecan-dependent manner.

We reasoned that, perhaps, the increased over-extension defects we observed in the integrated SDN-1 lines could also be due to the transgene interfering with normal EGL-20 activity. We reduced the amount of SDN-1 being produced by making the inserted juSi119 transgene heterozygous. In those animals, the over-extension phenotype was reduced from $59 \%$ to $21 \%$, suggesting the over-extension observed was SDN-1 dose-dependent. 
Syndecan and Wnt Axon Termination

\section{HS modifiers interact with LIN-44 and EGL-20 in a context-dependent manner}

Interactions between Wnt ligands and HSPGs are often mediated by the side chains present on the core protein. It has been demonstrated that the side chains on SDN-1 are modified by an epimerase, HSE-5, and at least two sulfotransferases, HST-2 and HST-6 (BERNFIELD et al. 1992; LeE AND CHIEN 2004). Each enzyme has been shown to be involved in multiple aspects of neural development through the specific modifications each makes (BULOW AND HOBERT 2004; RHINER et al. 2005; Bulow et al. 2008; DiAZBALZAC et al. 2014). We examined the loss-of-function mutation for the three modifying enzymes to determine whether heparan sulfate sugar modifications are important for interactions with EGL-20.

HSE-5 is a C5-epimerase that is predicted to catalyze the chain-modifying epimerization of glucuronic acid to iduronic acid during heparan sulfate biosynthesis. HSE-5 is predominantly expressed in the hypodermis and intestine (BULOW AND HOBERT 2004). Previously, HSE-5 has been shown to function in parallel to SDN-1 for D-type motorneuron dorsally-directed commissure outgrowth and VNC fasciculation (RHINER et al. 2005). Animals with loss of function in hse-5 exhibited both under-and overextension phenotypes in the DNC (Table 3), indicating that the activity of this enzyme does contribute to anterior/posterior outgrowth of D-type axons. Double mutants of $h s e-5$ and $s d n-1$ had an additive effect, inducing under-extension defects in $77 \% \pm 3$ animals, consistent with HSE-5 having targets in addition to SDN-1.

We subsequently asked whether loss of hse-5 affected the penetrance of defects in EGL-20dependent outgrowth (Table 3). The egl-20; hse-5 double mutants had fewer under-extended DNCs, consistent with EGL-20 inducing premature termination in animals lacking HSE-5 activity. The double 
Syndecan and Wnt Axon Termination

mutants were not significantly different for over-extended DNCs from egl-20 single mutants, suggesting the loss of hse-5 was not further affecting this phenotype.

HST-2 and HST-6 can add sulfate moieties to side chains after epimerization by HSE-5. During neuronal development $h s t-6$ is expressed in neuronal tissues and $h s t-2$ is expressed in the hypodermis (BULOW AND HOBERT 2004). We observed a lower penetrance of under-extension defects in hst-2 (23\%) and $h s t-6(13 \%)$ mutants compared to either hse-5 or sdn-1 mutants. However, like $h s e-5$ and $s d n-1$, we found that removing egl-20 resulted in a reduction in the penetrance of under-extension defects mutants in the transferase mutants (Table 3). Overall, we concluded that loss of the modifier enzymes was similar, but not equivalent to the loss of SDN-1, consistent with other reports of the core protein and modifiers to proteoglycan functions (DEJIMA et al. 2014; ZHENG et al. 2015b).

Table 3. DNC phenotypes in heparan sulfate modifying enzyme genes

\begin{tabular}{lcccccc} 
& \multicolumn{2}{c}{ \% Observed (Mean \pm St. Dev) } & \multicolumn{3}{c}{ Comparison to HS single mutant } \\
& Under & WT & Over & N & P (under) & P (over) \\
hse-5 & $45 \pm 2$ & $29 \pm 2$ & $27 \pm 4$ & 250 & & \\
hse-5; sdn-1 & $77 \pm 3$ & $17 \pm 8$ & $6 \pm 5$ & 201 & $<0.0001 \ddagger$ & $<0.0001 \ddagger$ \\
hse-5; egl-20 & $4 \pm 5$ & $28 \pm 4$ & $69 \pm 9$ & 112 & $<0.0001 \ddagger$ & $<0.0001 \ddagger$ \\
hst-2 & $17 \pm 8$ & $41 \pm 15$ & $42 \pm 6$ & 127 & & \\
hst-2; egl-20 & $8 \pm 12$ & $34 \pm 10$ & $58 \pm 1$ & 217 & 0.2366 & 0.0251 \\
hst-6 & $11 \pm 3$ & $48 \pm 23$ & $41 \pm 20$ & 137 & & \\
hst-6; egl-20 & $2 \pm 2$ & $34 \pm 13$ & $64 \pm 11$ & 246 & $0.0013 \ddagger$ & $0.0012 \ddagger$ \\
\multicolumn{2}{l}{ † Significantly different $(P<0.0063)$} & & & &
\end{tabular}

\section{sdn-1 is not compensated by glypican-like HSPG receptors}

Glypicans are a second family of membrane-associated HSPGs. In C. elegans there are two glypican family members, gpn-1 and lon-2 (HUDSON et al. 2006; GUMIENNY et al. 2007). Recent work has found a role for lon-2 in netrin-mediated axon guidance (BLANCHETTE et al. 2015). To determine if these receptors were the proteins modified by HSE-5 to function in parallel with SDN-1 we examined loss-of-function 20 | P a g e 
mutations in $g p n-1$ and lon-2, alone, and in combination with sdn-1. Overall, we found that removing Ion-2 alone had little effect on termination in the dorsal nerve cord. gpn-1 mutant animals displayed a penetrant over-extension phenotype (Table 4) that was reduced when lon-2 was removed. In contrast, in animals already lacking $s d n-1$ the removal of gpn-1 and/or lon-2 did not increase the penetrance of the under-extension phenotype. Based on these analyses we concluded that the glypican-like receptors are not the HSE-5-modified proteins that are in parallel to SDN-1 in dorsal cord outgrowth.

Table 4. DNC phenotypes in heparan sulfate-decorated receptors

\begin{tabular}{lcccccccc} 
& \multicolumn{2}{c}{ \% Observed (Mean \pm St. Dev) } & $\mathrm{N}$ & \multicolumn{2}{c}{ Comparison to sdn-1 } & $\%$ Pdn & N \\
& Under & WT & Over & $\mathrm{N}$ & $\mathrm{P}$ (under) & $\mathrm{P}$ (over) & & \\
gpn-1(ok377) & $2 \pm 2$ & $32 \pm 8$ & $66 \pm 7$ & 190 & $<0.0001 \ddagger$ & $<0.0001 \ddagger$ & $4 \pm 7$ & 202 \\
lon-2(e678) & $0 \pm 0$ & $85 \pm 10$ & $15 \pm 10$ & 107 & $<0.0001 \ddagger$ & 0.0657 & $1 \pm 1$ & 108 \\
gpn-1lon-2 & $6 \pm 9$ & $75 \pm 3$ & $19 \pm 9$ & 84 & $<0.0001 \ddagger$ & 0.4509 & $1 \pm 2$ & 85 \\
gpn-1sdn-1 & $36 \pm 15$ & $50 \pm 6$ & $16 \pm 8$ & 120 & 0.9068 & 0.0785 & $17 \pm 10$ & 142 \\
gpn-1lon-2sdn-1 & $34 \pm 5$ & $50 \pm 3$ & $14 \pm 9$ & 94 & 0.8988 & 0.0529 & $27 \pm 13$ & 126 \\
f Significantly different & & & & & & & &
\end{tabular}

\section{sdn-1 functions in a canonical Wnt signaling pathway to promote axon extension}

Wnt signaling in C. elegans has been well characterized. Like others systems, in a canonical signaling pathway, activation of Frizzled receptors by Wnt ligands activates the cytosolic protein Disheveled to inhibit the GSK3/Axin/APC complex, allowing $\beta$-catenin to activate the transcription of target genes with the help of TCF-LEF transcription factors (BUECHLING AND BOUTROS 2011). If EGL-20 were activating the canonical signaling pathway, then we would expect loss of function in downstream components to mimic the loss of egl-20. Instead, consistent with previous reports, we found some Wnt pathway mutants had both under- and over-extension defects in the DNC (Table 5). Mutations in lin-17/Frizzled (26\% \pm 2$)$, dsh1/Dishevelled $(28 \% \pm 0)$ or mig-5/Dishevelled $(55 \% \pm 2)$ each resulted in under-extension of the DNC, similar to data previously reported (MARO et al. 2009). 
Syndecan and Wnt Axon Termination

We created double mutants of $s d n-1$ with the above Wnt signaling genes. We found that removal of lin-17 did not grossly change the outcomes for DNC phenotypes from sdn-1 or lin-17 single mutants (Table 5), suggesting they were likely functioning in a common genetic pathway. Consistent with this we found that removing egl-20 from lin-17 resulted a reduction in the under-extension phenotype, as it had when we removed egl-20 from sdn-1 mutants (Table 5).

For Dishevelled, removing sdn-1 from the $d s h-1$ mutants resulted in an additive effect that was significantly different from either single mutant. The double mutants of $s d n-1$ and $m i g-5$ were nearly synthetic lethal, with only a very small percent ( $10 \%)$ of the animals surviving to adulthood. In those survivors, we observed under-extension, but it was not significantly different from mig-5 alone. Interestingly, although $d s h-1 ; s d n-1$ mutants were different, removing $d s h-1$ from mig-5 did not induce additional defects, as the animals appeared to be similar to mig-5 alone. We could partially rescue the extension defects in mig-5 animals by cell-specifically expressing mig-5 in the GABAergic neurons, using the unc-25 promoter (Table 5). Overall, we concluded sdn-1 and mig-5 function in parallel pathways during early development, but in the same pathway for DNC extension, with mig-5 epistatic to sdn-1.

Table 5. Frizzled and Disheveled DNC termination phenotypes

$$
\begin{aligned}
& \% \text { Observed (Mean } \pm \text { St. Dev) Comparison to } s d n-1 \\
& \begin{array}{lllll}
\text { lin-17 } & 26 \pm 2 & 36 \pm 21 & 38 \pm 19 & 230
\end{array} \\
& \begin{array}{lcccccc}
\text { lin-17; egl-20 } & 4 \pm 2 & 11 \pm 6 & 85 \pm 5 & 165 & 0.0188^{a} & 0.0028 \ddagger^{a} \\
\text { dsh-1 } & 28 \pm 0 & 65 \pm 5 & 8 \pm 5 & 166 & &
\end{array} \\
& \begin{array}{lcccccc}
\text { mig-5 } & 55 \pm 2 & 24 \pm 1 & 21 \pm 3 & 128 & & \\
\text { mig-5; Punc-25::rfp::mig-5 } & 24 \pm 7 & 65 \pm 12 & 11 \pm 7 & 185 & <0.0001^{b} & <0.0001^{b}
\end{array} \\
& \begin{array}{lllll}
\text { mig-5dsh-1 } & 56 \pm 6 & 44 \pm 6 & 0 \pm 0 & 137
\end{array} \\
& { }^{a} \text { comparison to egl-20 single }
\end{aligned}
$$$$
\begin{array}{lllllll}
\text { lin-17; sdn-1 } \quad 38 \pm 10 & 30 \pm 4 & 31 \pm 6 & 151 & 0.6656 & 0.0812
\end{array}
$$

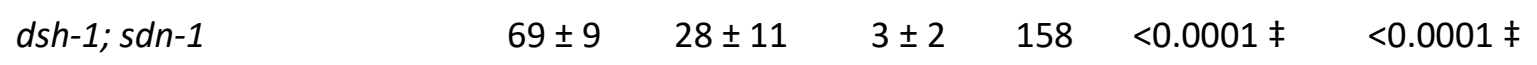$$
\begin{array}{lllllll}
\text { mig-5; sdn-1 } & 58 \pm 15 & 34 \pm 12 & 7 \pm 3 & 83 & <0.0001 \ddagger & 0.0104
\end{array}
$$$$
\text { ¥ Significantly different }(P<0.0063)
$$ 
Syndecan and Wnt Axon Termination

${ }^{b}$ compared to mig-5 single

\section{LIN-17 co-localizes with SDN-1 during neurite outgrowth in an EGL-20-dependent manner}

Our results suggested that LIN-17 was functioning in a manner largely equivalent to SDN-1. To determine if LIN-17 was localized to the DNC we expressed a full-length rescuing LIN-17::tagRFP chimera, under the control of the endogenous promoter (Figure 5) (Huarcaya Najarro and Ackley, 2013). LIN17::RFP was prevalent throughout the animal, including the posterior region of the dorsal nerve cord and surrounding tissues. We examined the localization of LIN-17::RFP relative to SDN-1::GFP in the juSi119 animals. We found an equivalent enrichment of LIN-17 and SDN-1 at the termination point of the DNC in wild-type animals.

Previous work suggested that LIN-17 localization in mechanosensory neurons was dependent on EGL-20/Wnt signaling. We asked whether this was true in the DNC by crossing the LIN-17::RFP and SDN1::GFP transgenes into egl-20 loss-of-function animals. We found that LIN-17 was no longer enriched in the posterior branch of the most posterior D-type neuron in young (L2) animals (Figure 5). However, later in development (L4) we could observe LIN-17 in the dorsal nerve cord in egl-20 mutants. Thus, we concluded that, with respect to localization to the region where GABAergic axons will terminate in the DNC, LIN-17 localization was partially egl-20-dependent.

\section{SDN-1 and EGL-20 require BAR-1 function during axon outgrowth}

In $C$. elegans the bar-1/ $\beta$-catenin gene is believed to be the primary transcriptional regulator for canonical Wnt signaling (EISENMANN ; NATARAJAN et al. 2001). The loss of bar-1/ $\beta$-catenin, results in a highly penetrant under-extension phenotype (Figure 6, Table 6); (MARO et al. 2009)). Removing either sdn-1 or 
Syndecan and Wnt Axon Termination

egl-20 from bar-1 mutants did not change the effect of bar-1 loss on axon termination (Table 6). Since animals with EGL-20 over-expression induced premature termination of the DNC, while loss of function mutations in egl-20 resulted in over-extension, our results suggested EGL-20 activity likely functioned to repress BAR-1 activity in DNC outgrowth, which is not a canonical outcome of Wnt-ligand signaling. We also examined lin-44; bar-1 double mutants and found, as had been previously described, an intermediate phenotype, with some animals having an over-extension phenotype. This is additional evidence that LIN-44 and EGL-20 were affecting the growth of the D-type neurons via distinct mechanisms.

Table 6. bar-1/ $\beta$-catenin DNC termination phenotypes

\begin{tabular}{lcccccc} 
& \multicolumn{2}{c}{$\%$ Observed (Mean \pm St. Dev) } & \multicolumn{2}{c}{ Comparison to bar-1 } \\
& Under & WT & Over & N & P (under) & P (over) \\
bar-1 & $96 \pm 1$ & $4 \pm 1$ & $0 \pm 0$ & 196 & & \\
bar-1; sdn-1 & $98 \pm 2$ & $2 \pm 2$ & $0 \pm 0$ & 170 & 0.5542 & 1 \\
bar-1; egl-20 & $89 \pm 4$ & $10 \pm 6$ & $1 \pm 2$ & 150 & 0.0242 & 0.1901 \\
bar-1; lin-44 & $65 \pm 21$ & $25 \pm 19$ & $11 \pm 2$ & 123 & $<0.0001 \ddagger$ & $<0.0001 \ddagger$ \\
$\quad$ ¥ Significantly different $(P<0.0125)$ & & & &
\end{tabular}

\section{MOM-2 is not required for initial DNC formation}

Since $96 \%$ of bar-1 animals were under-extended, we asked whether a third Wnt ligand, mom-2, could be responsible for promoting axon outgrowth. mom- 2 is expressed in the $\mathrm{L} 1$ stage, in the posterior of the animal near the region where the DNC is forming (HARTERINK et al. 2011). We examined maternallyrescued mom-2(or77) homozygotes and found no evidence of under-extension in the DNC, although we did see over-extension (Table 7). Removing mom-2 did not induce under-extension in the lin-44 or egl20 backgrounds. Triple mutants were sick and difficult to obtain, so we used RNAi to knockdown mom2 in lin-44; egl-20 double mutants. mom-2 RNAi caused a highly penetrant embryonic lethality, thus we 
collected escapers and analyzed the DNCs. We saw a higher than expected rate of under-extension in the escapers, but it was not as high as was observed in bar-1 single mutants. Thus, it is unlikely that MOM-2 was functioning to activate BAR-1 to promote axon extension from the commissural branch point to the normal termination point. RNAi of mom-2 in the animals lacking $s d n-1$ significantly reduced the number of under-extended DNCs, similar to the effect of removing egl-20, which is more consistent with MOM-2 functioning to promote normal termination.

Table 7. mom-2 DNC termination phenotypes

$\begin{array}{lcccccccc} & \text { \% Observed (Mean } \pm \text { St. Dev) } & \mathrm{N} & \text { Comparison to mom-2 } & \% \text { Pdn } & \text { N } \\ \text { mom-2(or77) [M+] } & 0 \pm 0 & 20 \pm 1 & 80 \pm 1 & 200 & & & 0 \pm 0 & 200 \\ \text { mom-2(or77) [M+]; lin-44 } & 0 \pm 0 & 11 \pm 14 & 89 \pm 14 & 128 & 1 & 0.0002 & 3 \pm 5 & 130 \\ \text { mom-2(or77) [M+]; egl-20 [M+] } & 3 \pm 2 & 21 \pm 25 & 76 \pm 23 & 242 & 0.0344 & 0.4569 & 1 \pm 2 & 243 \\ \text { mom-2[RNAi] } & 2 & 20 & 78 & 100 & & & 0 & 100 \\ \text { mom-2[RNAi]; lin-44; egl-20 } & 16 \pm 7 & 16 \pm 7 & 67 \pm 15 & 23 & 0.001 \neq a & 0.2799 a & 76 \pm 2 & 95 \\ \text { mom-2[RNAi]; sdn-1 } & 12 & 52 & 36 & 100 & <0.0001 \ddagger & 0.0331 & 14 & 116 \\ \quad \text { \# Significantly different (P<0.0063) } & & & & & & & \end{array}$

\section{The EGL-5 Hox gene contributes to the initial DNC formation and outgrowth}

Wnt signaling in C. elegans has been shown to function via many downstream mechanisms, including activating the transcription of Hox genes. The egl-5 Hox gene is expressed in the most posterior portion of the animal, including in the posterior D-type motorneurons, and surrounding tissues (NIU et al. 2011) (Figure 7). A loss of function mutation in egl-5(n945), recapitulated the bar-1 phenotype in the D-type neurons, causing a highly penetrant under-extended phenotype (95\%). We subsequently tested double mutants of $s d n-1$ with egl-5 and found that DNCs were almost entirely under-extended (89\%; $\mathrm{P}<0.001$ vs. $s d n-1$ and $\mathrm{P}=0.19$ vs egl-5) (Table 8 ), suggesting $s d n-1$ and egl-5 functioned in the same pathway. 
To determine if egl-5 was expressed in the DD and VD motorneurons we crossed an integrated Pegl5::EGL-5::GFP transgene (wg/s54) into a reporter for the GABAergic motorneurons (Punc-25::mCherry). We found, as has been reported, EGL-5::GFP expression was largely restricted to the posterior region. We observed co-incident expression of EGL-5::GFP and mCherry in the three most posterior neurons, VD12-DD6-VD13, with expression strongest in DD6 and VD13 (Figure 7). We observed expression in the posterior region of L1 animals, during the formation of the VD13 neuron (Figure 7), and expression was visible in the nascent VD13 (Figure 7) as soon as we could observe the differentiation marker (Punc-25) which occurs as the axons are initiating growth, prior to the formation of the dorsal process (NORRIS AND LUNDQUIST 2011) (Figure 2). Further, expression of EGL-5 was maintained in the neurons throughout development (L4 stage - Figure 7). Thus, we concluded that EGL-5 is expressed in the neurons (DD6 and VD13) that make posterior projections that terminate axon growth without the help of a more posterior D-type neuron, and that expression is maintained throughout the period of development when D-type neuron growth must be metered. We generated transgenic lines expressing egl-5 specifically in the Dtype neurons in the egl-5(n945) animals (Ih/s93). Cell-specific expression could partially rescue the underextension phenotype in egl-5 mutants (Table 8), suggesting egl-5 function was cell-autonomous.

To better understand the genetic pathway, we crossed the wgls54 transgene into the bar-1(ga80) mutants and found that expression of the egl-5::gfp was lost in the DD and VD neurons, but expression could be observed in other cells adjacent (Figure 7). This suggested that EGL-5 expression in the D-type neurons was bar-1-dependent, and that this might underlie the under-extension defects. Similar effects of Wnt signaling activating anterior vs. posterior behaviors in cells has been documented in the migration 
Syndecan and Wnt Axon Termination

of the Q-neuroblasts, with mab-5 necessary and sufficient for proper posterior growth (TAMAYO et al. 2013), and more recently in the axon outgrowth of PLM axons (ZHENG et al. 2015a).

We subsequently examined whether sdn-1 mutants also resulted in alterations in egl-5 expression. In contrast to bar-1, we did not find EGL-5::GFP expression to be lost from the D-type neurons in $s d n-1$ mutants. We did note however, the wgls54 transgene partially rescued axon-extension phenotypes present in the sdn-1 loss-of-function animals (Table 8). Thus, we concluded that underextension of the DNC in sdn-1 animals likely occurs via dysregulation of egl-5 expression in the GABAergic neurons, and that it is possible to partially bypass the requirement for SDN-1 in early dorsal nerve cord development by increasing the levels of EGL-5. It should be noted that this observation is consistent with the differences observed in the sdn-1 and bar-1 mutants, in the frequency of, as well as the position where axons prematurely terminated. Both aspects were more severe in bar-1 mutants than in sdn-1, and thus we do not believe sdn-1 mutations resulted in a complete loss of either bar-1 or egl-5 activity.

Table 8. egl-5 DNC termination phenotypes

\begin{tabular}{|c|c|c|c|c|c|c|}
\hline & \multicolumn{4}{|c|}{$\%$ Observed (Mean \pm St. Dev) } & \multicolumn{2}{|c|}{ Comparison to $s d n-1$} \\
\hline & Under & WT & Over & $\mathrm{N}$ & $\mathrm{P}$ (under) & $\mathrm{P}$ (over) \\
\hline egl-5 & $90 \pm 1$ & $10 \pm 1$ & $0 \pm 0$ & 194 & & \\
\hline egl-5; Ih/s93 & $10 \pm 2$ & $88 \pm 1$ & $4 \pm 3$ & 50 & $<0.0001 \ddagger^{*}$ & $0.204 \ddagger^{*}$ \\
\hline sdn-1; egl-5 & $89 \pm 3$ & $11 \pm 3$ & $0 \pm 0$ & 205 & $<0.0001 \ddagger$ & $<0.0001 \ddagger$ \\
\hline$w g / s 54$ & $1 \pm 1$ & $90 \pm 3$ & $9 \pm 4$ & 123 & & \\
\hline sdn-1; wgls54 & $17 \pm 1$ & $76 \pm 2$ & $7 \pm 2$ & 206 & $<0.0001 \ddagger$ & $<0.0001 \ddagger$ \\
\hline $\begin{array}{r}\mp \text { Significantly } \\
\left({ }^{*} \text { cor }\right. \\
(* * \text { co }\end{array}$ & $\begin{array}{l}\text { single } \\
1 s d n-1\end{array}$ & & & & & \\
\hline
\end{tabular}


Syndecan and Wnt Axon Termination

\section{Discussion}

\section{SDN-1 functions in anterior-posterior axon outgrowth and termination}

Neurons form neural networks by extending axons and dendrites into discrete regions where they can form synapses with targets. The complexity of network formation relies on extracellular cues being interpreted by cell-surface receptors, often with great precision and fidelity. Here we have found that two neuron types that terminate axon growth at stereotyped positions in the $C$. elegans nervous system are affected by the loss of the cell-surface receptor Syndecan/SDN-1. These results are consistent with sdn-1 regulating cell migration along the A/P axis (RHINER et al. 2005; SCHWABIUK et al. 2009). The disparate termination points and function of the distal tip cells, the GABAergic motorneurons and the posterior mechanosensory neurons, suggest that SDN-1 provides migration termination information broadly during organismal development.

In both GABAergic and mechanosensory neurons we found axons stopping short of, and growing past, their stereotyped termination point, even when other aspects (initial outgrowth, dorsal/ventral guidance, etc.) were grossly normal. Therefore, we concluded that the termination defects were, at least partially, independent of earlier guidance errors. Neither the PLMs nor the terminal D-type neurons (DD6 and VD13) have obvious cellular landmarks that indicate where they should terminate. This contrasts with the more anterior DD and VD neurons that terminate their posterior dorsal branch on the next DD or VD cell posterior, that is, the posterior branch of the VD11 dorsal process terminates where it meets the anterior branch of VD12, etc. Because of the overlap of the DD and VD axons in the dorsal nerve cord, it is not simple to determine whether $s d n-1$ has a broader role in regulating the outgrowth of dorsal branches in the D-type neurons along the anterior-posterior axis of the animal, and thus we focused 
Syndecan and Wnt Axon Termination

solely in this work on those in the posterior-most region. Our results suggest that SDN-1 modulates Wnt signaling to facilitate axon outgrowth early in development, and subsequently to maintain axon extension to be allometric with organismal growth as development progresses.

\section{SDN-1 function is both autonomous and non-autonomous}

In the D-type neurons we found an early role for SDN-1 in ensuring that the posterior neurite of the dorsal nerve cord reached the proper termination point. Based on rescue experiments, SDN-1 appeared to function cell-nonautonomously, as we could rescue the defects by expressing SDN-1 with an sdn-1 promoter, but not when we replaced SDN-1 specifically in the D-type neurons (Figure 8). We found that sdn-1 mutants exhibited an over-growth phenotype, where the axons grew past the normal termination point. This phenotype appeared to be cell-autonomous, as we could largely rescue this phenotype by specifically replacing SDN-1 in the GABAergic neurons. Thus, we concluded that SDN-1 is necessary in the D-type neurons to prevent overgrowth. Within the D-type neurons the PDZ-binding motif (EFYA) was required for the proper localization and function of SDN-1.

One result that was somewhat curious was the rescue of $s d n-1$ phenotypes by the integrated transgenes with the endogenous $s d n-1$ promoter. We could rescue the under-growth phenotype, and other sdn-1 phenotypes, including uncoordinated movement and male mating (data not shown), but not the over-extension phenotype. We found no evidence that SDN-1 expressed from the integrated transgenes was expressed in the D-type neurons, despite previous reports that the gene is expressed there (RHINER et al. 2005). It is certainly possible that the levels of expression are below detection, or that expression was delayed relative to when we conducted our analyses. However, we did find that we could 
Syndecan and Wnt Axon Termination

rescue the over-extension by D-type cell-specific expression. Thus, we concluded that, for reasons that are not yet understood, two, separately developed SDN-1 MosSCl inserted transgenes, were not being well expressed in the $\mathrm{D}$-type neurons. Other transgenes integrated via $\mathrm{MosSCl}$ at that position do express well in the D-type neurons (BDA, personal observations), and thus it is not clear why the SDN-1 transgenes are not.

\section{SDN-1 functions with EGL-20 to regulate axon termination}

Our sdn-1 rescue experiments did confirm that both the under-and over-growth phenotypes were due to loss of function in $s d n-1$. Further, the cell-specific expression of $s d n-1$ suggests a model whereby SDN-1 is acting outside the D-type neurons to facilitate growth from the commissural branch point to the normal termination point. In animals lacking both $s d n-1$ and egl-20 we found fewer animals with under-extended axons, suggesting that SDN-1 was negatively regulating EGL-20 during the initial axon outgrowth. This is consistent with our evidence and previous reports that EGL-20 primarily functions to inhibit axon outgrowth. Support for this hypothesis came from our observation that we could induce premature axon termination by over-expressing EGL-20, and that we could exacerbate the effects of EGL-20 over-expression by removing SDN-1, consistent with an antagonistic role for SDN-1 in this event.

We found that SDN-1 appeared to be aggregated near the site where axons would initially terminate. A simple model then would be that SDN-1 regulates the local accumulation of EGL-20 near the presumptive axon termination point. However, while the axon terminates near places we see EGL-20 accumulating, we do not necessarily see EGL-20 becoming enriched near the termination point, relative to adjacent regions. Thus, it is possible that SDN-1 accumulation has additional functions, either by 
Syndecan and Wnt Axon Termination

regulating the accumulation of other ligands, or forming a complex with EGL-20 that has differential activity with respect to axon termination. regulates the accumulation of multiple, coordinated ligands at the termination point, and it is the aggregate activity of these ligands that terminates axon growth.

After the initial role in antagonizing EGL-20, we found that SDN-1 was required cell-autonomously to promote termination of the axon during allometric growth of the D-type neurons. In this capacity, SDN-1 and EGL-20 appear to function equivalently, as loss of function in either resulted in axons that could grow past the normal termination point. Our epistasis experiments suggested that $s d n-1$ acted genetically downstream of EGL-20/Wnt, but with the LIN-17/Frizzled, and upstream of the MIG5/Dishevelled, BAR-1/ $\beta$-catenin and EGL-5/Hox transcription factor. Similar types of results suggesting a co-receptor role that can both promote and inhibit Wnt signaling have previously been demonstrated for the CAM-1/Ror tyrosine kinase, which has been referred to as a Wnt co-receptor (FORRESTER et al. 1999; Forrester et al. 2004; Green et al. 2007; HAyASH et al. 2009; KenNeRdell et al. 2009; OHAMA AND HAYASH 2009; MINAMI et al. 2010; SONG et al. 2010). Interestingly, the cell-autonomous function of SDN1 required the EFYA motif, which, in vertebrates, links syndecans to PDZ-domain containing proteins. Here we found that MIG-5/Dishevelled is required for axon outgrowth. MIG-5, like most Dishevelled proteins, contains a PDZ domain, central to the protein. Whether MIG-5 and SDN-1 physically interact remains to be determined empirically, but if they do, our evidence would suggest SDN-1 acts to inhibit MIG-5 to limit axon outgrowth. 
Syndecan and Wnt Axon Termination

\section{HS modifiers regulate the activity of EGL-20}

SDN-1 is the most prominent HSPG in C. elegans as detected by an antibody that recognizes the stubs of HS side chains resulting from heparitinase treatment (HUDSON et al. 2006). We found that enzymes that modify the heparan sulfate side chains, partially recapitulated the loss of function in sdn-1, but likely represent the loss of HS-chains on multiple core proteins, as sdn-1 and hse-5 double mutants had an additive effect. However, we did not find evidence that those core proteins are the glypican-like receptors, suggesting perhaps another HSPG is functioning in this pathway. With the primary candidates for this being UNC-52/perlecan and CLE-1/collagen XVIII.

Like the loss of $s d n-1$, removing egl-20 from animals with mutations in the modifier enzymes resulted in fewer under-extended DNCs, consistent with an apparent increase in EGL-20 activity (or range of activity) when animals had deficits in HS-modification. Our results are consistent with the modifications being important in mediating proteoglycan interactions with EGL-20. Interestingly, EGL-20 has a polybasic region (AA288-303 RKATKRLRRKERTERK) that is absent from the other posteriorly expressed Wnt ligands LIN-44 and MOM-2. Thus, it is conceivable that EGL-20 interactions are electrostatically favorable with proteins that have been modified with acidic-HS side chains, although this would require a more thorough biochemical analysis and remains hypothetical at this point.

\section{Wnt ligands antagonize but BAR-1 and EGL-5 promote posterior axon outgrowth}

In canonical signaling the Wnt ligand binding to Frizzled results in increased $\beta$-catenin activity. Here, although egl-20 appears to inhibit growth, we find that bar-1//-catenin activity promotes axon outgrowth. Interestingly, in the bar-1 mutants, the posterior branch of the axon in the dorsal cord is 
Syndecan and Wnt Axon Termination

almost entirely absent, although the anterior branch is typically intact. This suggests that perhaps, bar1 is required for the earliest events of axon outgrowth in the posterior branch, although how that would be differentially regulated from the formation of the anterior branch is curious. Ultimately, our results are consistent with previous work demonstrating that bar-1 acts as a switch for axon growth. When bar1 is absent axons are shortened, and when bar-1 degradation is inhibited axons are overgrown (MARO et al. 2009).

Our results suggested that Wnt ligands were not functioning to activate BAR-1 signaling, rather, it appears to be the opposite. In the PLM neurons, recent work has demonstrated that Dishevelled proteins likely regulate the repellant activities of Wnt signaling, by modulating the phosphorylation state of Frizzleds (ZHENG et al. 2015a). However, we find that, in the D-neurons, there are some important differences, including opposite effects of loss of Wnt ligands and Disheveled. Further, in the PLM neurons there was only a modest effect on axon growth due to the loss of bar-1, but we found a strong effect on GABAergic outgrowth. One possibility is that the effects are somehow different on the anteriorly growing PLM axons, compared to the posteriorly directed D-type axons.

Thus, it is not yet clear how BAR-1 is activated in the D-type neurons to promote axon outgrowth, nor how Wnt signaling is inhibiting BAR-1 signaling in these neurons. rpm-1(an E3 ubiquitin ligase) and anc-1(a Nesprin family member) also appear to function in neurons to potentiate bar-1 signaling (TULGREN et al. 2014). Thus, it is possible that, some amount of Wnt ligand activity initiates BAR-1 signaling, and this can support axonal development due to the function of RPM-1 and ANC-1.

In the D-type neurons BAR-1 appeared to be necessary to activate the expression of EGL-5, and loss of egl-5 activity largely recapitulates the bar-1 mutant phenotype. Other Hox genes, for example mab- 
5, have been shown to be both necessary and sufficient for the posterior growth of the $Q$ neuroblast descendants (TAMAYO et al. 2013). Thus, it is possible that egl-5 has a similar role in the D-type neurons. However, we did not necessarily observe increased axon outgrowth in the anterior of the animal when EGL-5 is driven ectopically in the anterior D-type neurons. This could be due to a different program of axon outgrowth in those neurons, or that EGL-5 is more specifically required for axon outgrowth in the posterior D-type neurons, but that it is most easily observed in the posterior branch of the dorsal cord.

\section{Wnt-dependent mechanism of axon termination}

The wire-minimization hypothesis suggests that axon pathfinding has evolved to provide a balance between the length of process, which reduce neuronal efficiency, and the necessary routing (MILLERFLEMING et al. 2016). Consequently, it is likely that organisms evolved multiple, redundant signals to regulate aspects of pathfinding, including where axons will choose to terminate. Wnt signaling is a primary force in the anterior-posterior guidance of neurons across the animal kingdom (Zou 2004; FENSTERMAKER et al. 2010). Here we have found that multiple Wnt ligands collaborate with the syndecan HSPG to regulate the termination of D-type neurons in a stereotyped position. Although these molecules demonstrate a somewhat complicated pattern of genetic interactions, our results are consistent with them being necessary to reproduce the stereotyped termination of the GABAergic motorneurons in the dorsal nerve cord. 
bioRxiv preprint doi: https://doi.org/10.1101/046094; this version posted June 13, 2017. The copyright holder for this preprint (which was not certified by peer review) is the author/funder, who has granted bioRxiv a license to display the preprint in perpetuity. It is made available under aCC-BY-NC-ND 4.0 International license.

Syndecan and Wnt Axon Termination

\section{Acknowledgements}

We would like to thank Katsu Dejima and Andrew Chisholm for sharing the juSi119 MosSCI insertion prior to publication. We would also like to thank Riley Roberts, Vi Leitenberger, Erik Lundquist and Michael Branden for useful discussion and technical support during this work. This work was supported in part by awards from the NIH (P20GM103418 and P20GM103638). 
bioRxiv preprint doi: https://doi.org/10.1101/046094; this version posted June 13, 2017. The copyright holder for this preprint (which was not certified by peer review) is the author/funder, who has granted bioRxiv a license to display the preprint in perpetuity. It is made available under aCC-BY-NC-ND 4.0 International license.

Syndecan and Wnt Axon Termination

\section{Figures}

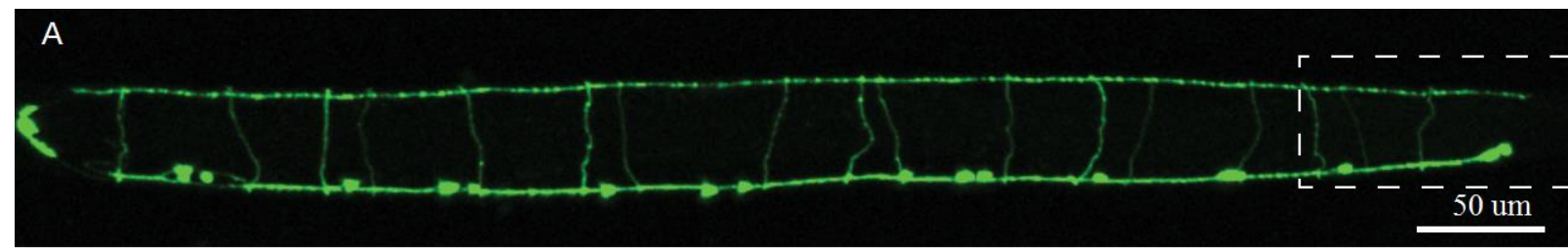

wild type
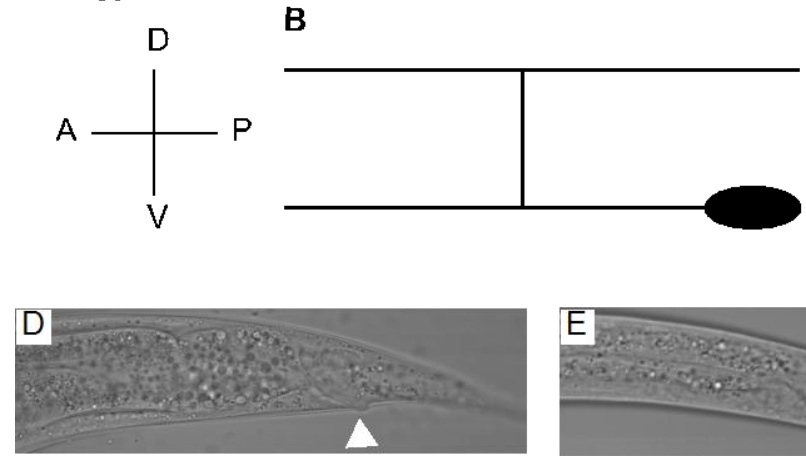

\section{wild type}

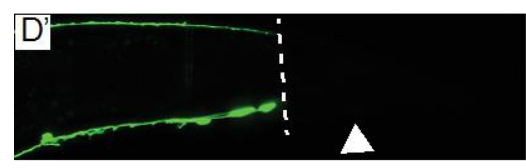

D"

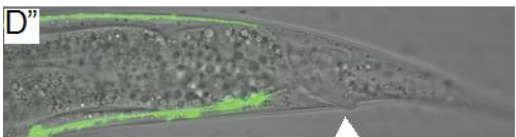

G

wild type PLM termination

sdn-1(zh20)
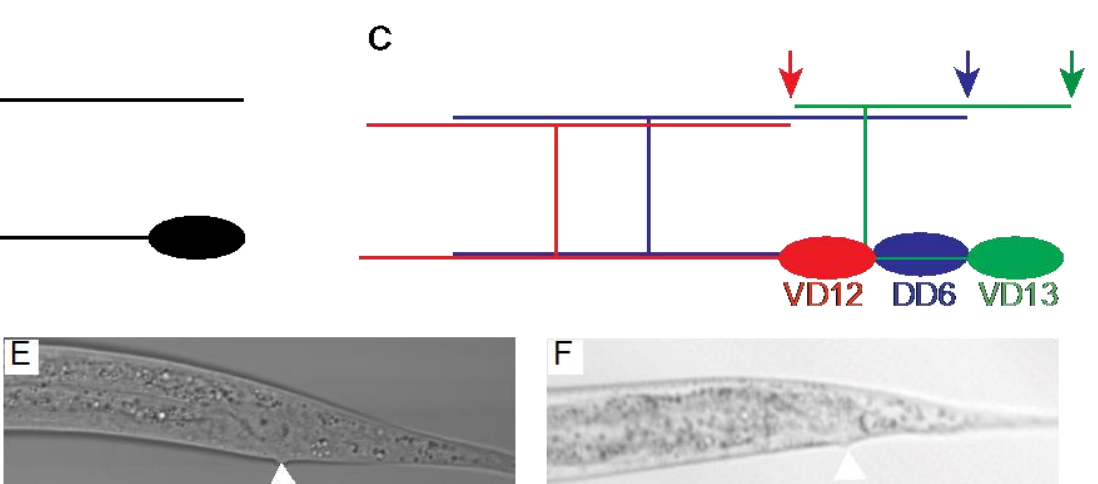

F

sdn-1(zh20)
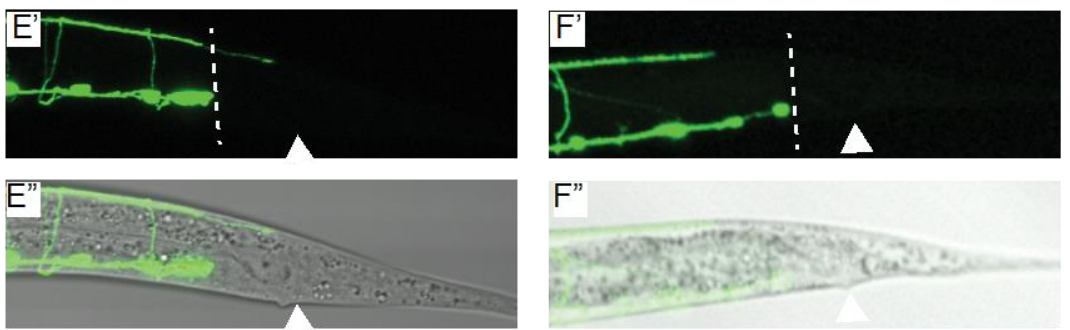

$F^{\prime \prime}$

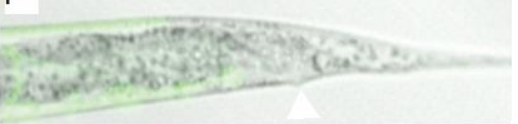

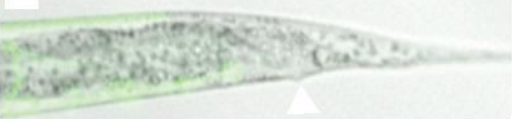

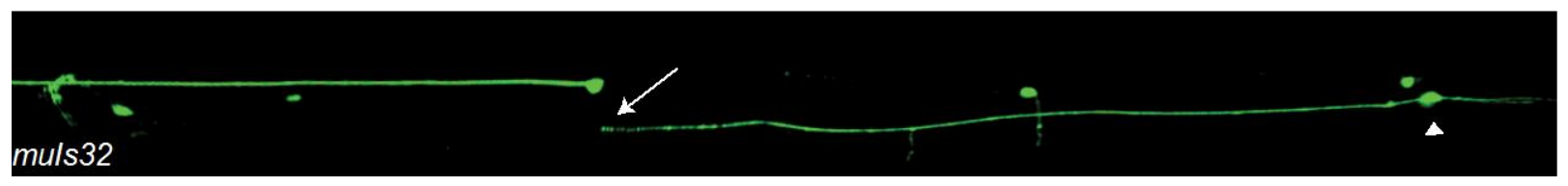

$\mathbf{H}$

PLM over growth

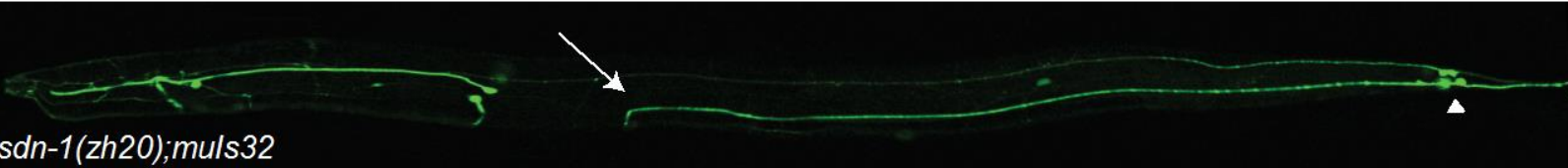


Syndecan and Wnt Axon Termination

\section{Figure 1 - $s d n-1$ regulates VD13 termination in the DNC}

A) In an L4 wild-type juls76 [Punc-25::gfp] animal it is possible to visualize the pattern of axon growth of the GABAergic motorneurons, anterior is left and ventral down in all images. Boxed region in $(A)$ is the tail region equivalent to those presented in (D-F). B) A schematic of the expected morphology of a generic D-type or V-type GABAergic motorneuron, the posterior branch of the dorsal projection terminates approximately at the posterior edge of the cell body. C) A schematic of the terminal three neurons, VD12, DD6 and VD13 and approximate termination points are indicated by arrows. D) A wild type L4 animal where the dorsal nerve cord terminates in a line with the cell bodies (dashed line). The arrowhead indicates the position of the anus. E) An sdn-1(zh20) L4 animal with an over-extended DNC, progressed past the plane of the last cell body, and is approximately at the position of the anus. F) An sdn-1(zh20) L4 animal with an under-extended DNC, terminating at approximately the position of the DD6 cell body. In wild-type muls32 animals the PLM (arrowhead indicates PLM cell body) axons terminate (arrow) along the anterior-posterior axis around the position of the ALM soma. B) In sdn1(zh20) mutants we find that some PLM axons reach the normal termination point and then turn ventrally to continue growth, over-extending. C) Loss of function in lin-44/Wnt can result in PLM axons that grow posteriorly and then turn anteriorly, making the PLM appear reversed. D) lin-44 mutants can also display PLMs were the anterior branch and posterior branch are of approximately equal length. E) The number of animals presenting with each type of PLM growth defect. 
bioRxiv preprint doi: https://doi.org/10.1101/046094; this version posted June 13, 2017. The copyright holder for this preprint (which was not certified by peer review) is the author/funder, who has granted bioRxiv a license to display the preprint in perpetuity. It is made available under aCC-BY-NC-ND 4.0 International license.

Syndecan and Wnt Axon Termination

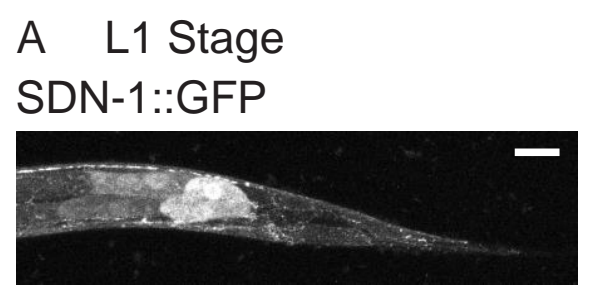

B L2 Stage

C L4 Stage
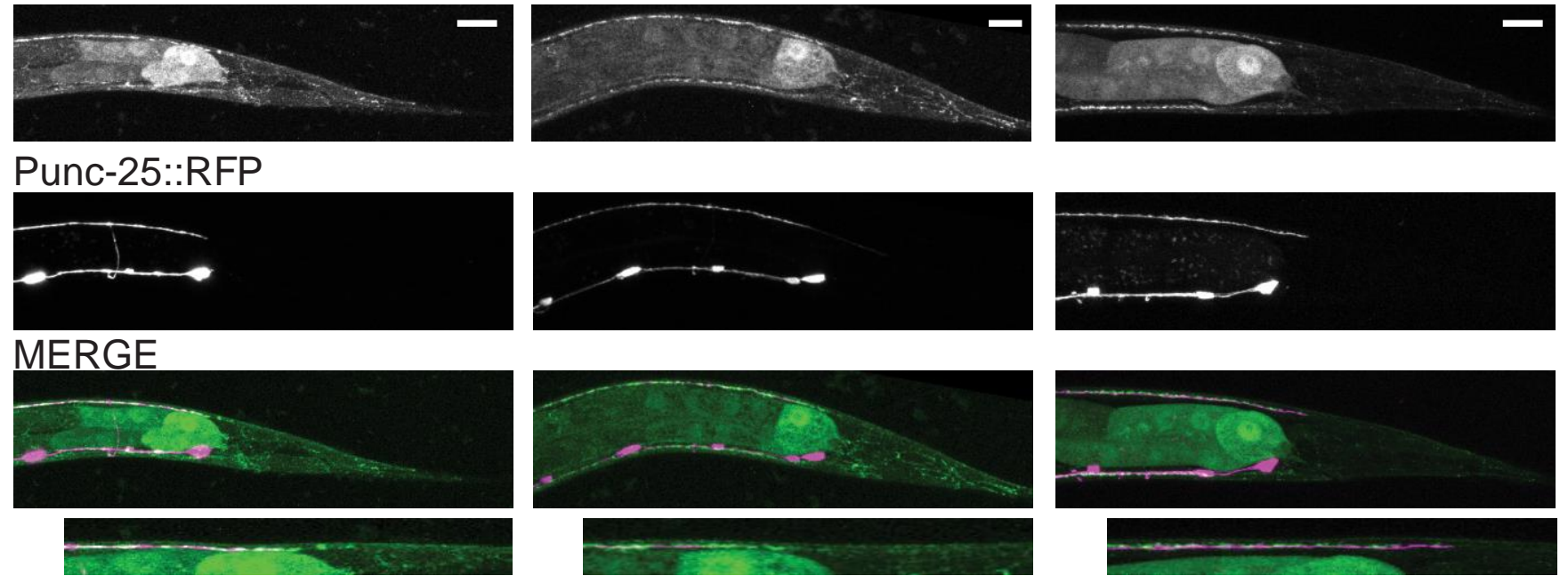

Intensity Profile
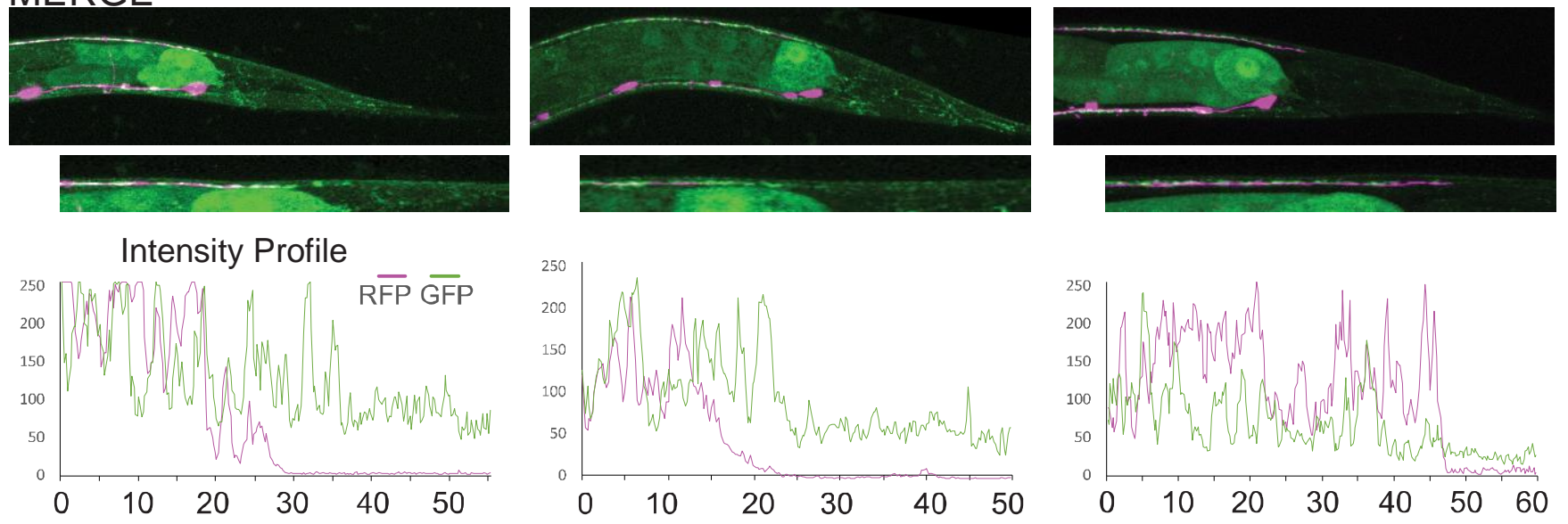

D early L2 stage
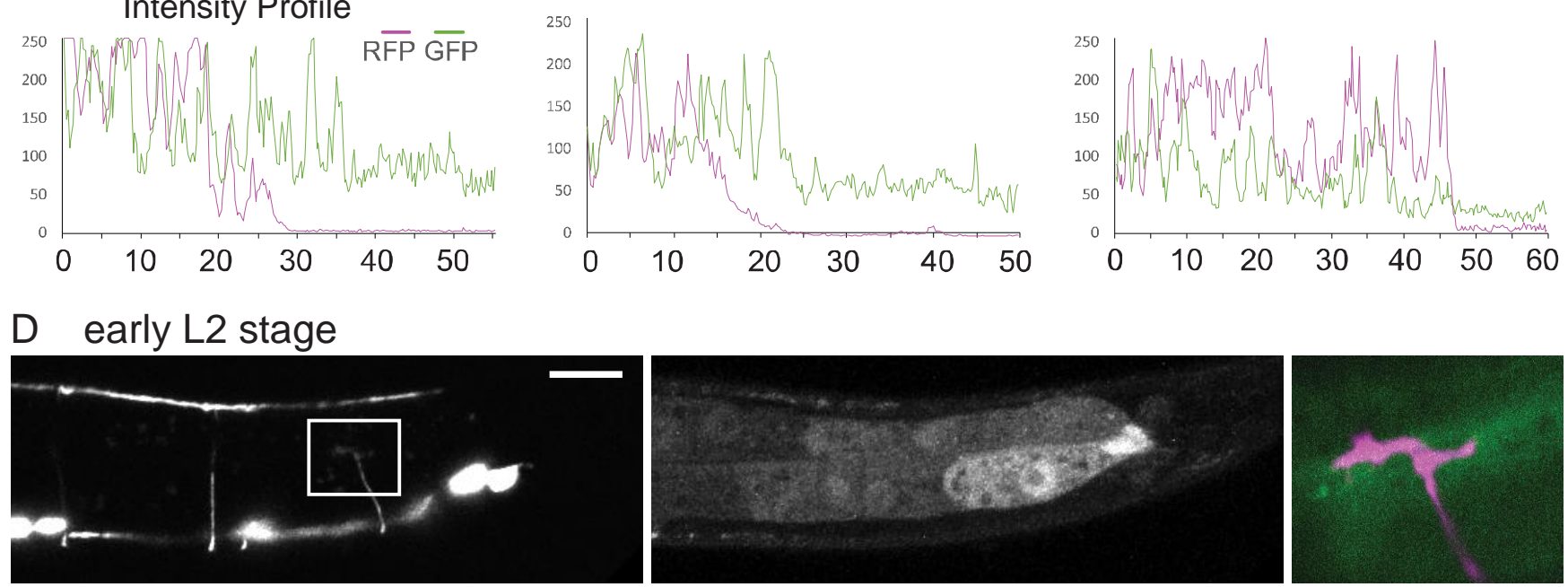

\section{E Punc-25::SDN-1::GFP}
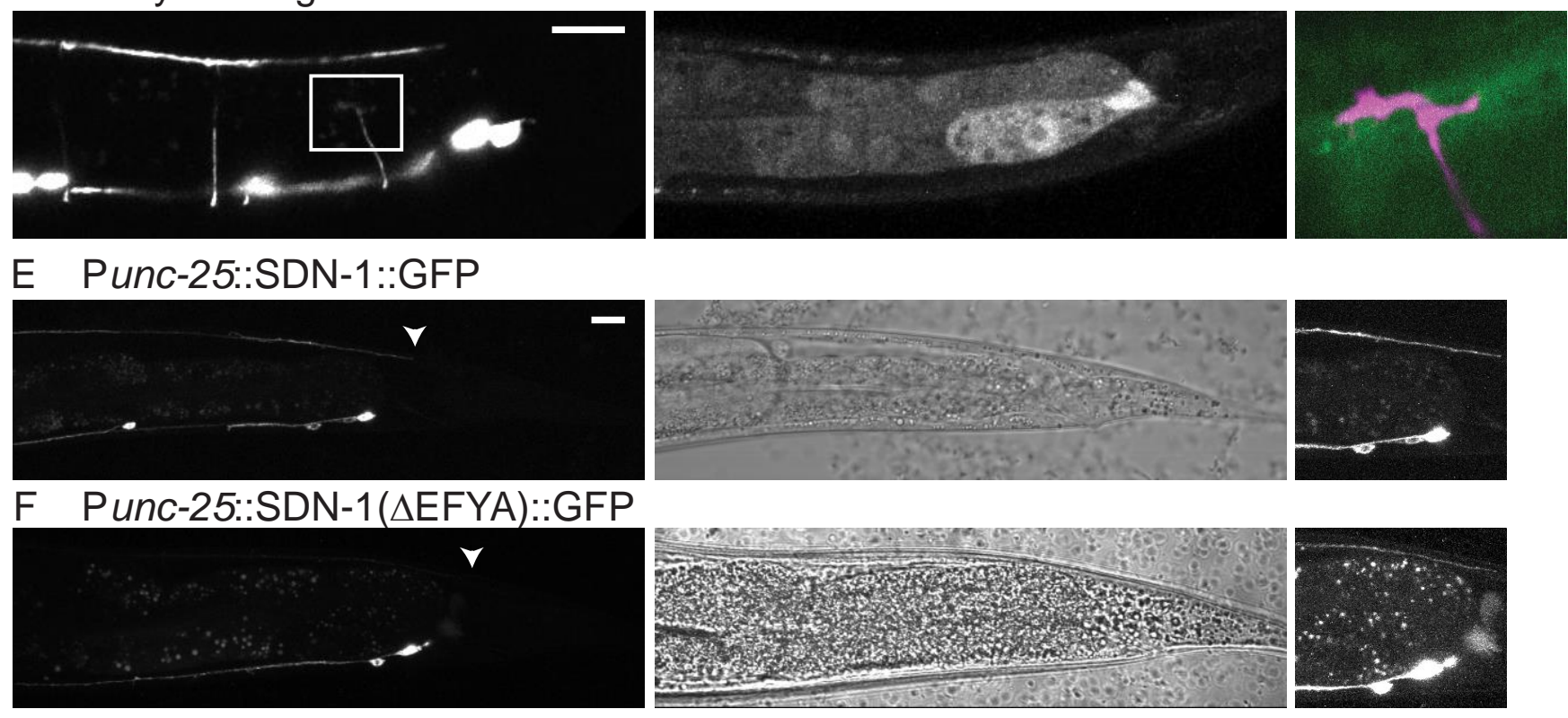
Syndecan and Wnt Axon Termination

\section{Figure 2 - SDN-1::GFP accumulates near the D-type termination point in the dorsal nerve cord}

SDN-1::GFP expression (juSi119) relative to the D-type neurons (Punc-25::RFP). A) In wild-type first larval stage animals (L1) GFP was present in the tail in multiple tissues, and was localized to the dorsal nerve cord. Line scans were generated by drawing a 1-pixel wide line along the dorsal nerve cord, and measuring the intensity using the Plot Profile command in ImageJ. The graphs illustrate the accumulation of SDN-1 near the end of the GABAergic DNC. No gross differences in the accumulation of SDN-1 were observed as the animals aged through the L2 (B) and L4 (C) larval stages. D) SDN-1::GFP was not obviously localized to the growth cone of the VD13 neuron during outgrowth. E) Expression of an SDN-1::GFP chimera specifically in the D-type neurons. SDN-1 localized primarily to the dorsal and ventral nerve cords, and was present near the expected termination (arrowhead). F) Removal of the EFYA motif from the SDN-1::GFP resulted in a reduced localization to the dorsal cord. At the right, the contrast enhanced image demonstrates that, although reduced, the SDN-1( $\triangle E F Y A):: G F P$ was able to localize to the dorsal cord. 


\section{Syndecan and Wnt Axon Termination}
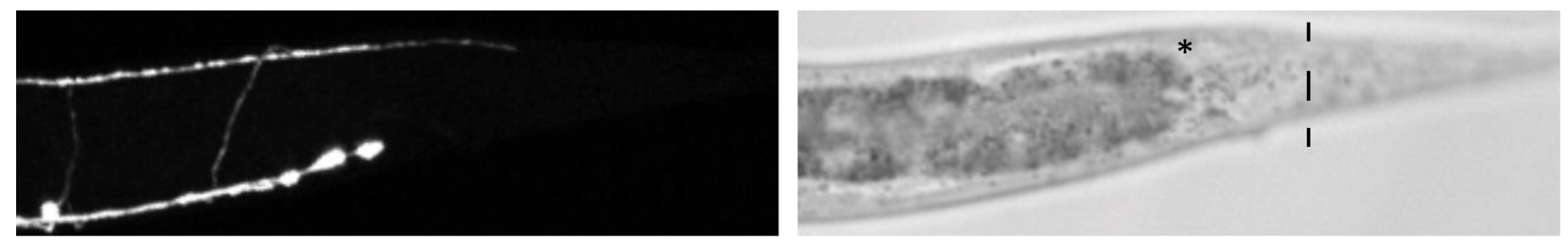

lin-44(n1792)
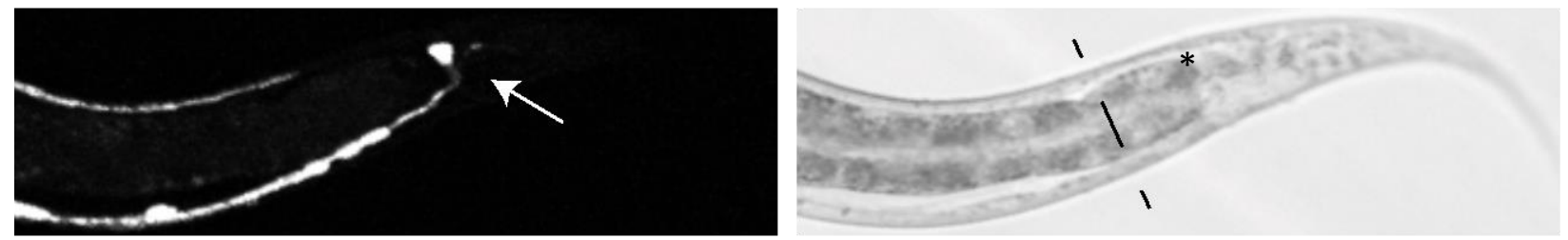

lin-44(n1792);sdn-1(zh20)
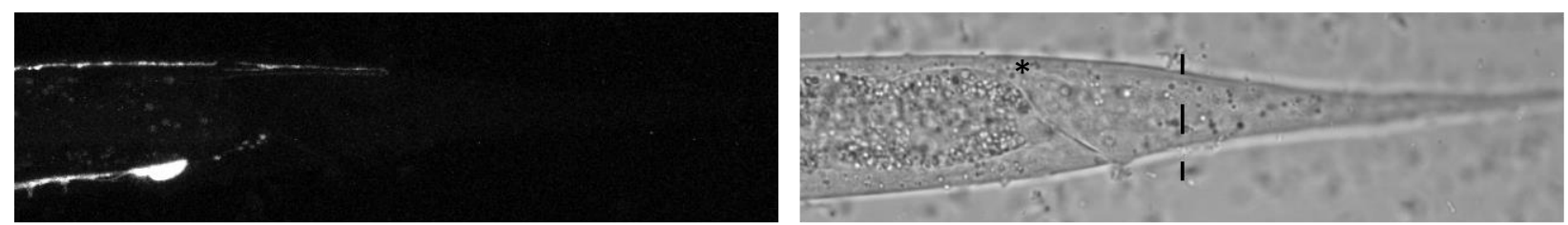

lin-44(n1792);sdn-1(zh20)
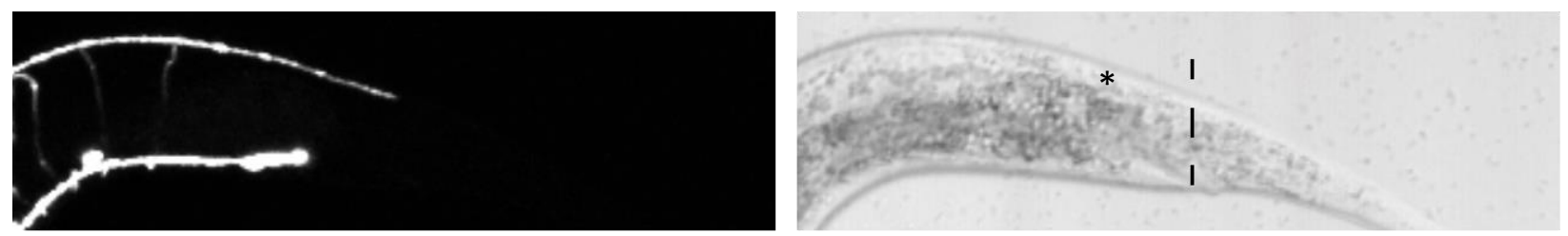

egl-20(gk453010) 
bioRxiv preprint doi: https://doi.org/10.1101/046094; this version posted June 13,2017 . The copyright holder for this preprint (which was not certified by peer review) is the author/funder, who has granted bioRxiv a license to display the preprint in perpetuity. It is made available under aCC-BY-NC-ND 4.0 International license.

Syndecan and Wnt Axon Termination

Figure 3 - lin-44 and egl-20 Wnt ligands regulate the termination point of the dorsal nerve cord

Loss of function mutations in lin-44 resulted in the DNC overextending into the posterior regions of the animal. The arrowhead indicates the expected termination point. In the DIC image the dashed line indicates the termination point of the axon fascicle in the animal. The asterisks indicate the approximate wild-type termination point. Note, the second lin-44; zh20 animal was visualized using oxls12, which is linked to sdn-1 on LG X, and also labels the DVB neuron (arrow), which is located just posterior and slightly dorsal to the VD13 cell body. Loss of function in egl-20 also resulted in over-extension of the DNC. 
Syndecan and Wnt Axon Termination

Pegl-20::EGL-20::GFP
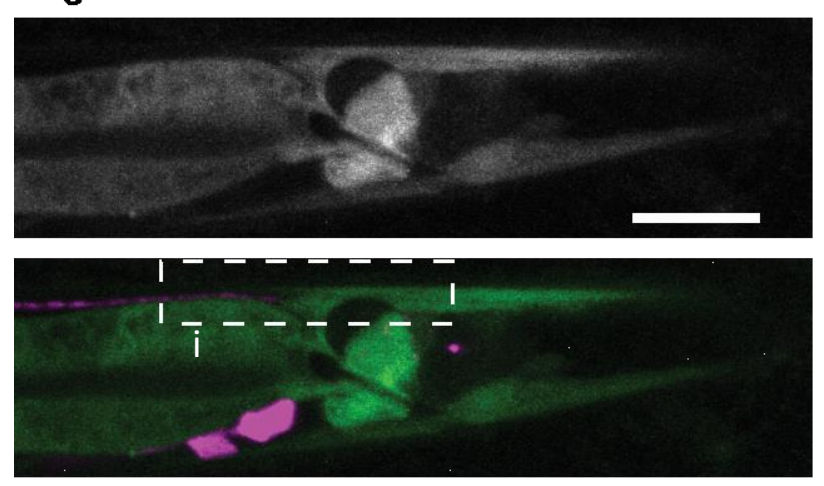
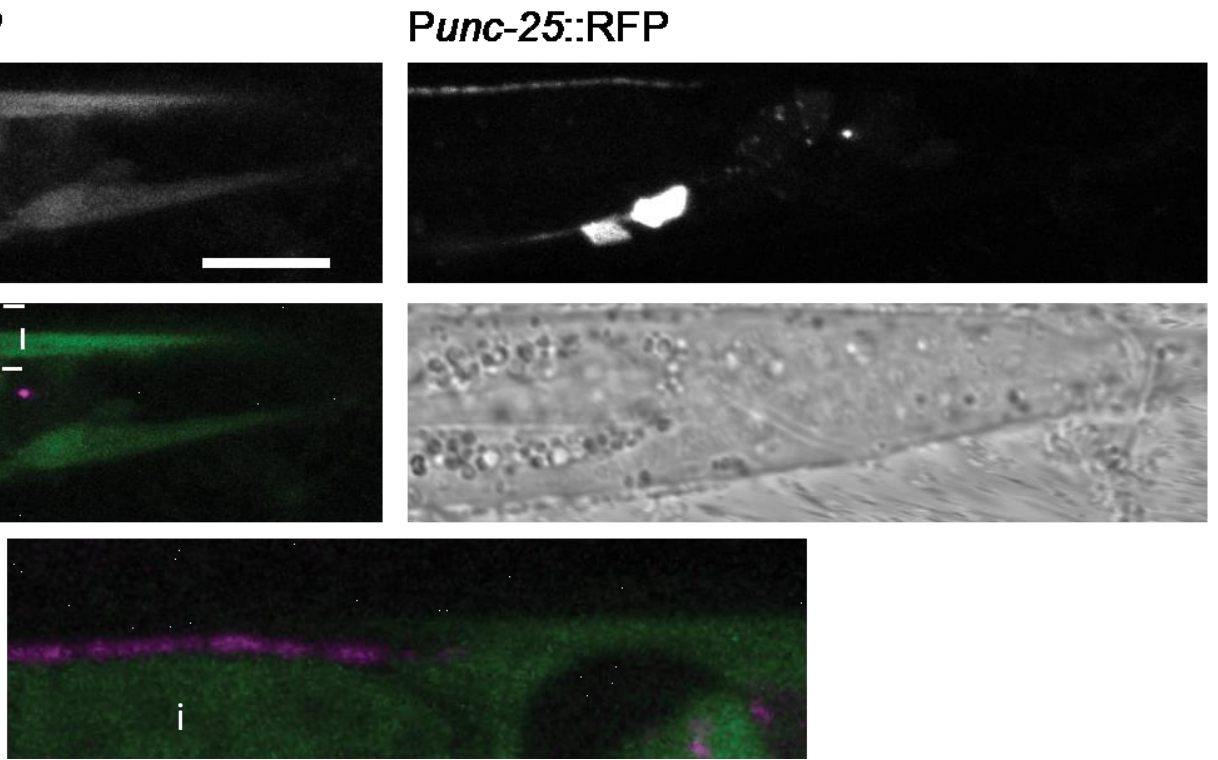

Figure 4 - The GABAergic neurons terminate near regions where EGL-20 accumulates

EGL-20::GFP localized to the posterior of the animals, near the muscles and relative to the termination point of the GABAergic neurons in L2 animals. Note the GFP in the intestine (i) is an artifact of the coinjection marker, and is intracellular. 
Syndecan and Wnt Axon Termination
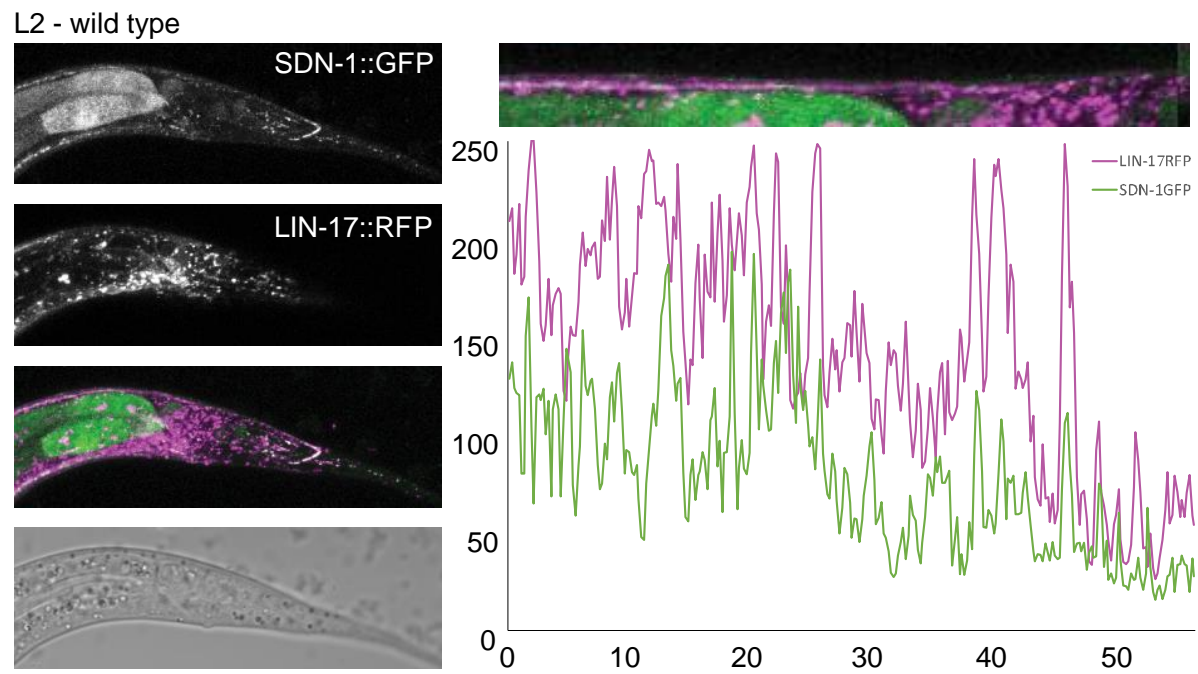

L2 - egl-20(gk453010)
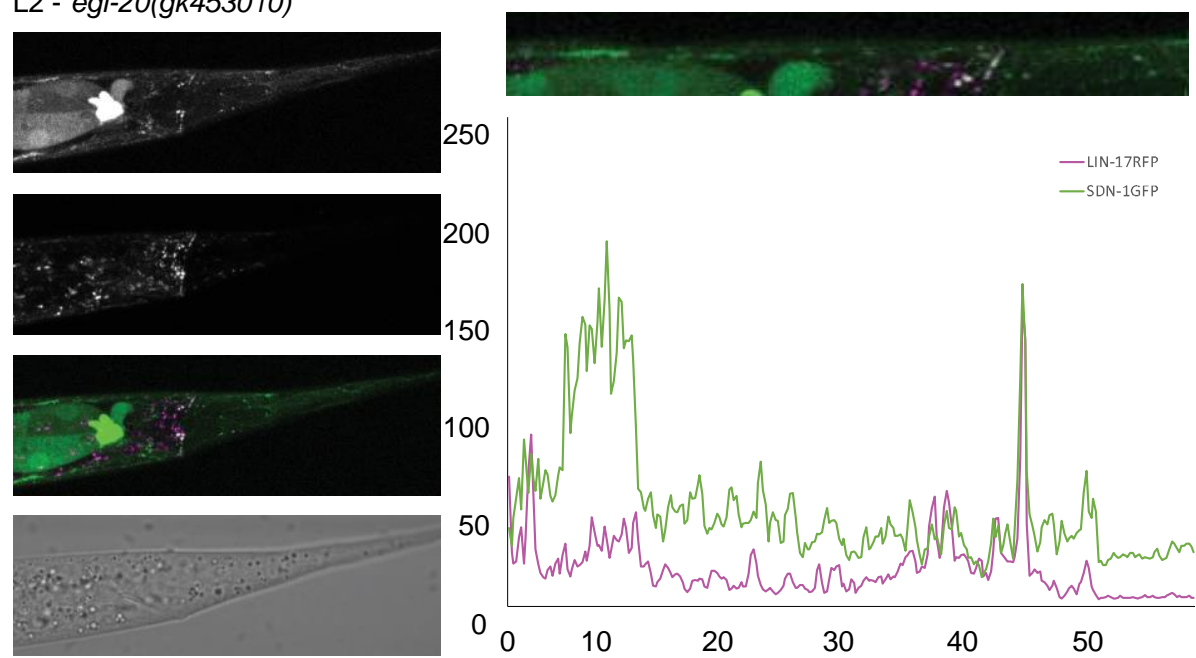

Figure 5 - SDN-1 and LIN-17 co-localize to the dorsal nerve cord in an egl-20-dependent manner

Loss of function in sdn-1 and lin-17 had similar effects on axon outgrowth, and the proteins appear to co-localize in the dorsal nerve cord in L2 animals. Conversely, in egl-20 loss of function animals while SDN-1::GFP localization was present, LIN-17::RFP accumulation was reduced, especially within the dorsal nerve cord. 


\section{Syndecan and Wnt Axon Termination}

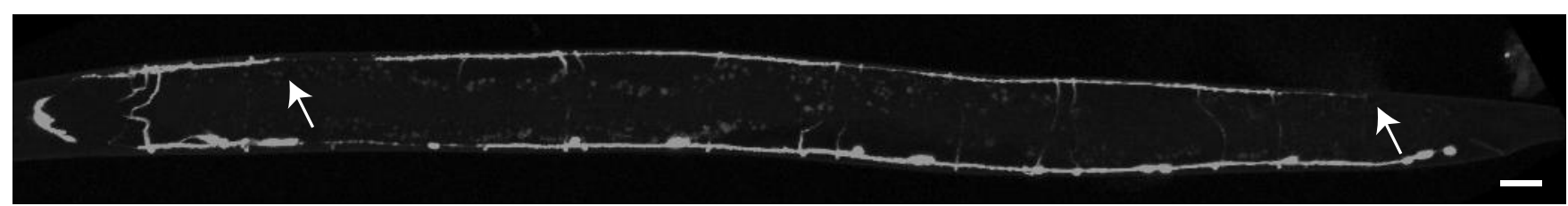

bar-1(ga80)

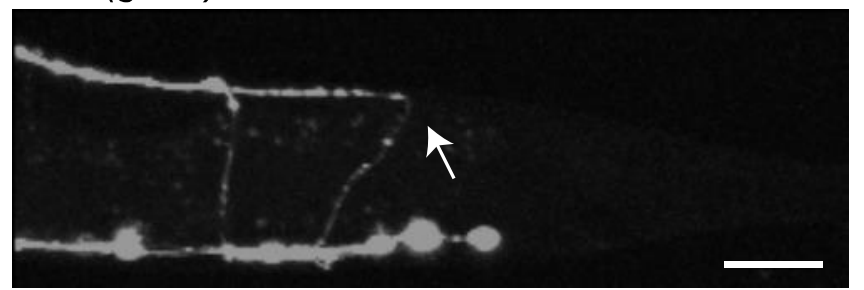

bar-1(ga80)
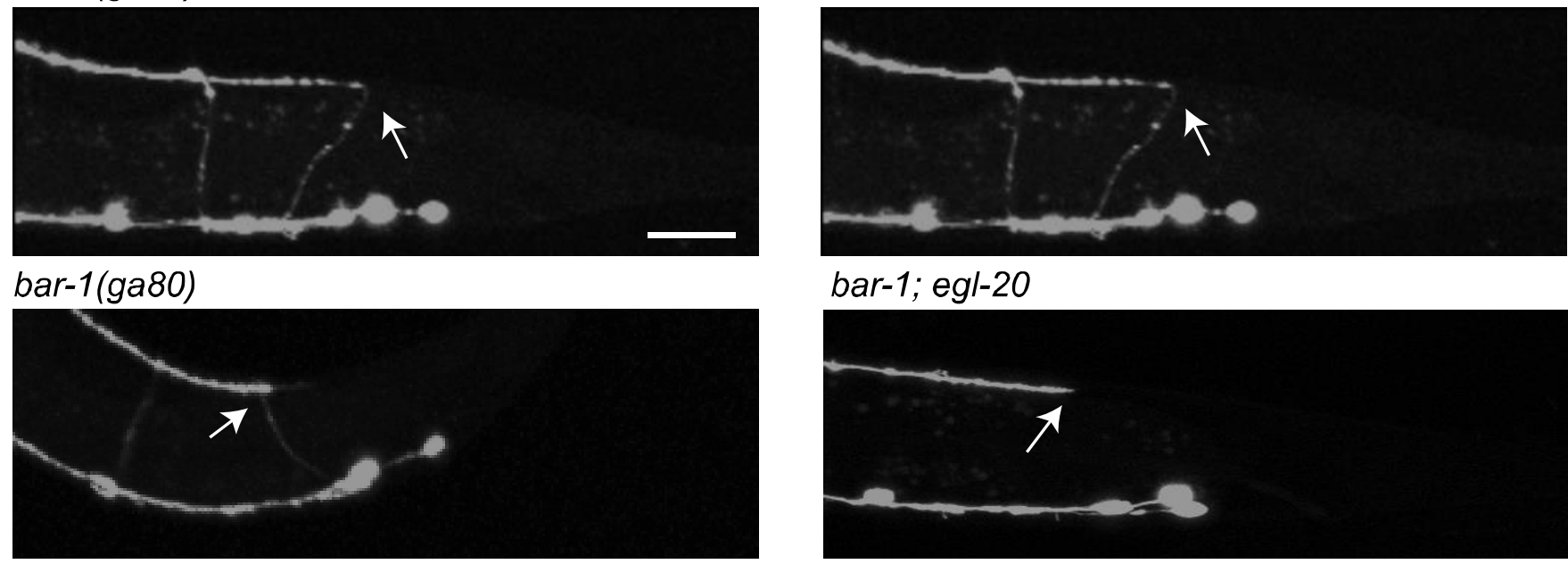

bar-1; egl-20

egl-5(n945)

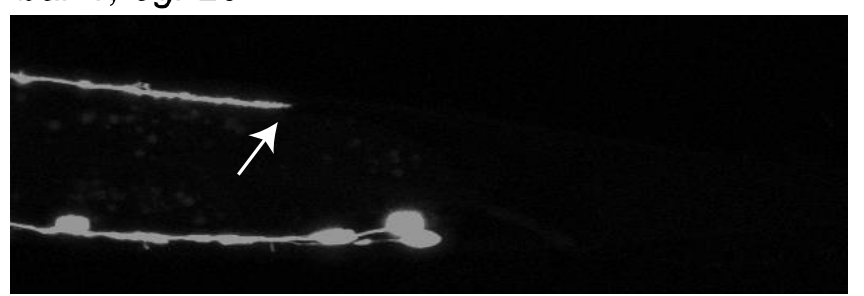

egl-5; sdn-1

Figure 6 - Axon underextension in bar-1 and egl-5 mutants

The D-type neurons in bar-1 mutants exhibited premature termination (arrows). Specifically, in the tail, most frequently the posterior branch of the dorsal axon fails to form or was shortened. egl-5 mutants had a similar phenotype, with an axon that grew only a short distance from the commissural branch point. 
bioRxiv preprint doi: https://doi.org/10.1101/046094; this version posted June 13, 2017. The copyright holder for this preprint (which was not certified by peer review) is the author/funder, who has granted bioRxiv a license to display the preprint in perpetuity. It is made available under aCC-BY-NC-ND 4.0 International license.

\section{Syndecan and Wnt Axon Termination}
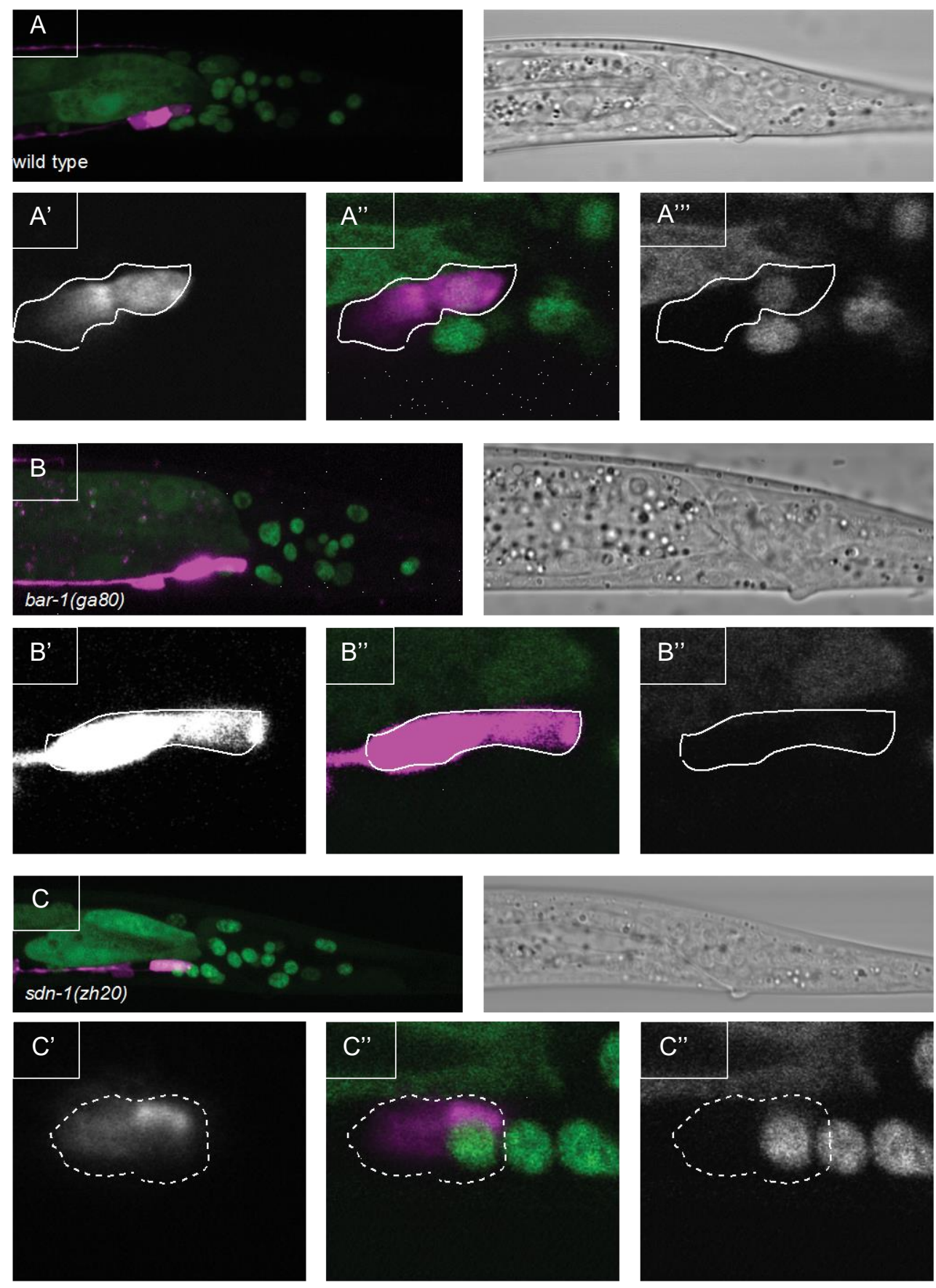
Syndecan and Wnt Axon Termination

Figure 7 - EGL-5GFP is expressed in the GABAergic motorneurons in a bar-1-dependent manner

We examined the expression of EGL-5 using a Pegl-5::EGL-5::GFP transgene that rescued the mutant defects associated with the (n945) phenotype. A) In wild-type animals EGL-5::GFP was expressed in the most posterior D-type neurons, along with other cells in the tail. The image is a projection of a Z-stack through the tail. $\left(A^{\prime}-A^{\prime \prime \prime}\right)$ Single planes containing the VD13 nucleus are illustrated for Punc-25::rfp ( $\left.A^{\prime}\right)$ merge $\left(A^{\prime \prime}\right)$ and Pegl-5::egl-5::gfp ( $\left.A^{\prime \prime \prime}\right)$. Note that EGL-5::GFP is present in the nucleus of VD13, but also in DD6 (cell anterior), but the nucleus is out of the plane capture. B) Loss-of-function in bar-1 results in a loss of EGL-5 expression in the D-type neurons, but a complete loss of EGL-5 expression altogether. B'$\left.\mathrm{B}^{\prime \prime \prime}\right)$ Single plane images through the VD13 nucleus, as above. C) Loss of function in sdn-1 does not recapitulate the bar-1 loss of egl-5 expression. $\left.C^{\prime}-C^{\prime \prime \prime}\right)$ Single plane images through VD13 nucleus, as above. Note, the cell bodies of DD6 and VD13 are circled in all panels. 
Syndecan and Wnt Axon Termination

Outgrowth From Commissure

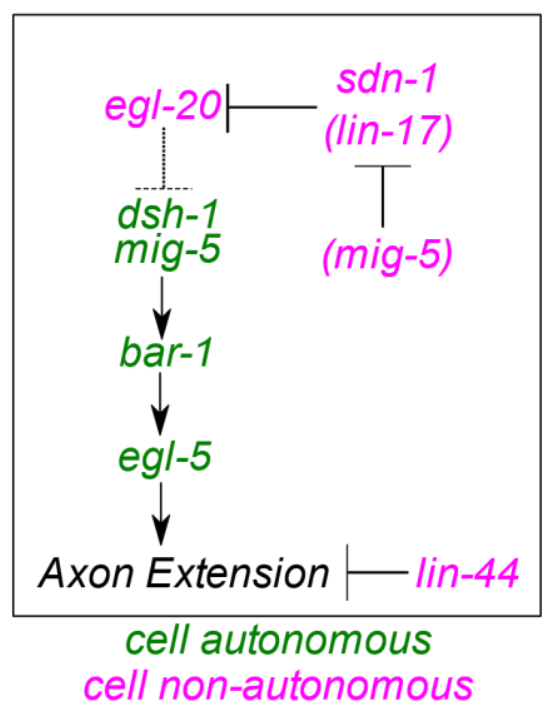

Developmental Growth

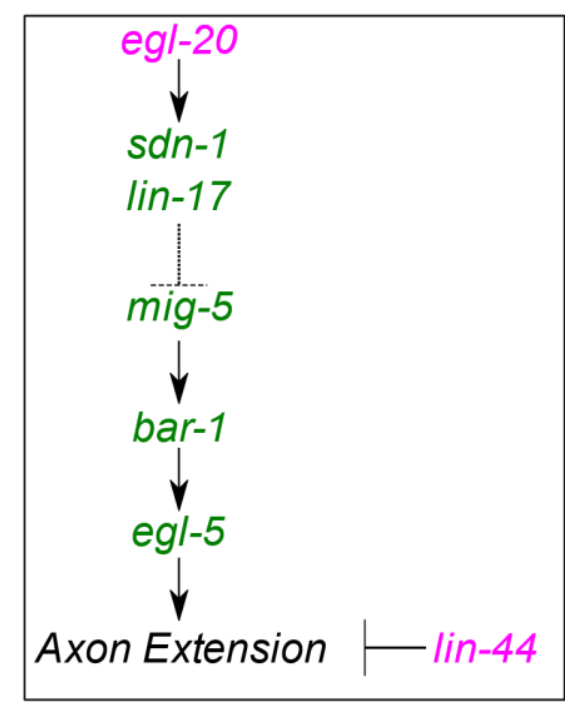

\section{Figure 8 - Genetic model}

A simplified genetic model suggests that egl-20 and lin-44 exhibit independent effects on the extension of axons into the posterior of the animal. In the egl-20 pathway, we found a cell-nonautonomous role for $s d n-1$ in the early outgrowth of the commissure, where sdn-1 appears to inhibit the activity of egl20. We infer that mig-5 and lin-17 have non-autonomous roles, due to the phenotypic consequences and the lack of complete rescue for mig-5 by cell-specific expression. Within the D-neurons the link between egl-20 appears to inhibit the activities of $d s h-1$, mig-5, bar-1 and egl-5, all of which promote axon extension. Later in development, as the animal is increasing in size, the function for sdn-1 appears cell autonomous, and it now appears to function with egl-20 to inhibit axon extension, by inhibiting the activity of the mig-5, bar-1, egl-5 components that promote outgrowth. 
Syndecan and Wnt Axon Termination

PLM reversed

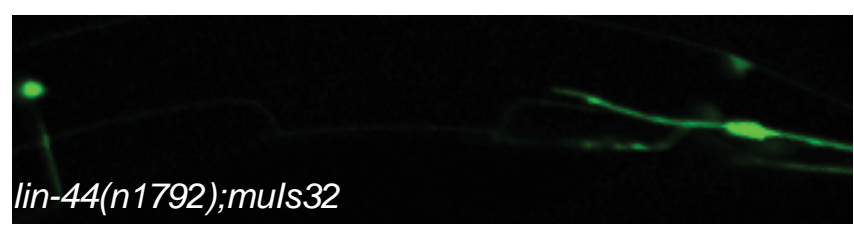

PLM equal

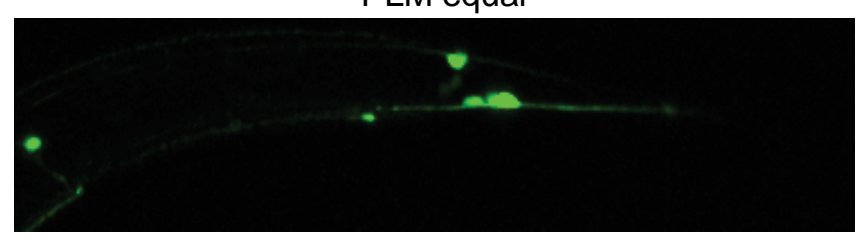

\section{Supplementary Figure 1 - PLM defects in lin-44 mutants}

PLM neurons in lin-44 mutants were often observed with reversed morphologies, where the posterior

branch of the axon is much longer than the anterior branch. The axon projected into the tail and then

turn anterior projecting past the cell body. In other animals, the anterior and posterior branches

exhibit approximately equal lengths. 
Syndecan and Wnt Axon Termination

\section{Literature Cited}

Alexander, C. M., F. Reichsman, M. T. Hinkes, J. Lincecum, K. A. Becker et al., 2000 Syndecan-1 is required for Wnt-1-induced mammary tumorigenesis in mice. Nat Genet 25: 329-332.

Aricescu, A. R., I. W. McKinnell, W. Halfter and A. W. Stoker, 2002 Heparan sulfate proteoglycans are ligands for receptor protein tyrosine phosphatase sigma. Mol Cell Biol 22: 1881-1892.

Baeg, G. H., and N. Perrimon, 2000 Functional binding of secreted molecules to heparan sulfate proteoglycans in Drosophila. Curr Opin Cell Biol 12: 575-580.

Bernfield, M., R. Kokenyesi, M. Kato, M. T. Hinkes, J. Spring et al., 1992 Biology of the syndecans: a family of transmembrane heparan sulfate proteoglycans. Annu Rev Cell Biol 8: 365-393.

Bishop, J. R., M. Schuksz and J. D. Esko, 2007 Heparan sulphate proteoglycans fine-tune mammalian physiology. Nature 446: 1030-1037.

Blanchette, C. R., P. N. Perrat, A. Thackeray and C. Y. Benard, 2015 Glypican Is a Modulator of Netrin-Mediated Axon Guidance. PLoS Biol 13: e1002183.

Brenner, S., 1974 The genetics of Caenorhabditis elegans. Genetics 77: 71-94.

Buechling, T., and M. Boutros, 2011 Wnt signaling signaling at and above the receptor level. Curr Top Dev Biol 97: 21-53.

Bulow, H. E., and O. Hobert, 2004 Differential sulfations and epimerization define heparan sulfate specificity in nervous system development. Neuron 41: 723-736.

Bulow, H. E., N. Tjoe, R. A. Townley, D. Didiano, T. H. van Kuppevelt et al., 2008 Extracellular sugar modifications provide instructive and cell-specific information for axon-guidance choices. Curr Biol 18: 1978-1985.

Chan, S. S., H. Zheng, M. W. Su, R. Wilk, M. T. Killeen et al., 1996 UNC-40, a C. elegans homolog of DCC (Deleted in Colorectal Cancer), is required in motile cells responding to UNC-6 netrin cues. Cell 87: 187-195.

Colamarino, S. A., and M. Tessier-Lavigne, 1995 The axonal chemoattractant netrin-1 is also a chemorepellent for trochlear motor axons. Cell 81: 621-629.

Dejima, K., S. Kang, S. Mitani, P. C. Cosman and A. D. Chisholm, 2014 Syndecan defines precise spindle orientation by modulating Wnt signaling in C. elegans. Development 141: 4354-4365.

Diaz-Balzac, C. A., M. I. Lazaro-Pena, E. Tecle, N. Gomez and H. E. Bulow, 2014 Complex cooperative functions of heparan sulfate proteoglycans shape nervous system development in Caenorhabditis elegans. G3 (Bethesda) 4: 1859-1870.

Drescher, U., F. Bonhoeffer and B. K. Muller, 1997 The Eph family in retinal axon guidance. Curr Opin Neurobiol 7: 75-80.

Edwards, T. J., and M. Hammarlund, 2014 Syndecan promotes axon regeneration by stabilizing growth cone migration. Cell Rep 8: 272-283.

Eisenmann, D., Wnt signaling, pp. WormBook.

Fenstermaker, A. G., A. A. Prasad, A. Bechara, Y. Adolfs, F. Tissir et al., 2010 Wnt/planar cell polarity signaling controls the anterior-posterior organization of monoaminergic axons in the brainstem. J Neurosci 30: 16053-16064.

Forrester, W. C., M. Dell, E. Perens and G. Garriga, 1999 A C. elegans Ror receptor tyrosine kinase regulates cell motility and asymmetric cell division. Nature 400: 881-885.

Forrester, W. C., C. Kim and G. Garriga, 2004 The Caenorhabditis elegans Ror RTK CAM-1 inhibits EGL-20/Wnt signaling in cell migration. Genetics 168: 1951-1962.

Green, J. L., T. Inoue and P. W. Sternberg, 2007 The C. elegans ROR receptor tyrosine kinase, CAM-1, nonautonomously inhibits the Wnt pathway. Development 134: 4053-4062. 
bioRxiv preprint doi: https://doi.org/10.1101/046094; this version posted June 13,2017 . The copyright holder for this preprint (which was not

certified by peer review) is the author/funder, who has granted bioRxiv a license to display the preprint in perpetuity. It is made available under aCC-BY-NC-ND 4.0 International license.

Syndecan and Wnt Axon Termination

Grill, B., W. V. Bienvenut, H. M. Brown, B. D. Ackley, M. Quadroni et al., 2007 C. elegans RPM-1 regulates axon termination and synaptogenesis through the Rab GEF GLO-4 and the Rab GTPase GLO-1. Neuron 55: 587-601.

Gumienny, T. L., L. T. MacNeil, H. Wang, M. de Bono, J. L. Wrana et al., 2007 Glypican LON-2 is a conserved negative regulator of BMP-like signaling in Caenorhabditis elegans. Curr Biol 17: 159-164.

Harterink, M., D. H. Kim, T. C. Middelkoop, T. D. Doan, A. van Oudenaarden et al., 2011 Neuroblast migration along the anteroposterior axis of $C$. elegans is controlled by opposing gradients of Wnts and a secreted Frizzled-related protein. Development 138: 2915-2924.

Hartin, S. N., M. L. Hudson, C. Yingling and B. D. Ackley, 2015 A synthetic lethal screen identifies a role for lin44/Wnt in C. elegans embryogenesis. PLoS One In Press.

Hayashi, Y., T. Hirotsu, R. Iwata, E. Kage-Nakadai, H. Kunitomo et al., 2009 A trophic role for Wnt-Ror kinase signaling during developmental pruning in Caenorhabditis elegans. Nat Neurosci 12: 981-987.

Hilliard, M. A., and C. I. Bargmann, 2006 Wnt signals and frizzled activity orient anterior-posterior axon outgrowth in C. elegans. Dev Cell 10: 379-390.

Hobert, O., K. Tessmar and G. Ruvkun, 1999 The Caenorhabditis elegans lim-6 LIM homeobox gene regulates neurite outgrowth and function of particular GABAergic neurons. Development 126: 1547-1562.

Huang, X., H. J. Cheng, M. Tessier-Lavigne and Y. Jin, 2002 MAX-1, a novel PH/MyTH4/FERM domain cytoplasmic protein implicated in netrin-mediated axon repulsion. Neuron 34: 563-576.

Huang, X., P. Huang, M. K. Robinson, M. J. Stern and Y. Jin, 2003 UNC-71, a disintegrin and metalloprotease (ADAM) protein, regulates motor axon guidance and sex myoblast migration in C. elegans. Development 130: 3147-3161.

Huarcaya Najarro, E., and B. D. Ackley, 2013 C. elegans fmi-1/flamingo and Wnt pathway components interact genetically to control the anteroposterior neurite growth of the VD GABAergic neurons. Dev Biol 377: 224-235.

Hudson, M. L., T. Kinnunen, H. N. Cinar and A. D. Chisholm, 2006 C. elegans Kallmann syndrome protein KAL-1 interacts with syndecan and glypican to regulate neuronal cell migrations. Dev Biol 294: 352-365.

Inatani, M., F. Irie, A. S. Plump, M. Tessier-Lavigne and Y. Yamaguchi, 2003 Mammalian brain morphogenesis and midline axon guidance require heparan sulfate. Science 302: 1044-1046.

Josephson, M. P., Y. Chai, G. Ou and E. A. Lundquist, 2016 EGL-20/Wnt and MAB-5/Hox Act Sequentially to Inhibit Anterior Migration of Neuroblasts in C. elegans. PLoS One 11: e0148658.

Kennedy, T. E., T. Serafini, J. R. de la Torre and M. Tessier-Lavigne, 1994 Netrins are diffusible chemotropic factors for commissural axons in the embryonic spinal cord. Cell 78: 425-435.

Kennerdell, J. R., R. D. Fetter and C. I. Bargmann, 2009 Wnt-Ror signaling to SIA and SIB neurons directs anterior axon guidance and nerve ring placement in C. elegans. Development 136: 3801-3810.

Lee, J. S., and C. B. Chien, 2004 When sugars guide axons: insights from heparan sulphate proteoglycan mutants. Nat Rev Genet 5: 923-935.

Maro, G. S., M. P. Klassen and K. Shen, 2009 A beta-catenin-dependent Wnt pathway mediates anteroposterior axon guidance in C. elegans motor neurons. PLoS ONE 4: e4690.

Miller-Fleming, T. W., S. C. Petersen, L. Manning, C. Matthewman, M. Gornet et al., 2016 The DEG/ENaC cation channel protein UNC-8 drives activity-dependent synapse removal in remodeling GABAergic neurons. Elife 5.

Minami, Y., I. Oishi, M. Endo and M. Nishita, 2010 Ror-family receptor tyrosine kinases in noncanonical Wnt signaling: their implications in developmental morphogenesis and human diseases. Dev Dyn 239: 1-15.

Minniti, A. N., M. Labarca, C. Hurtado and E. Brandan, 2004 Caenorhabditis elegans syndecan (SDN-1) is required for normal egg laying and associates with the nervous system and the vulva. J Cell Sci 117: 5179-5190.

50 I P a g e 
Natarajan, L., N. E. Witwer and D. M. Eisenmann, 2001 The divergent Caenorhabditis elegans beta-catenin proteins BAR-1, WRM-1 and HMP-2 make distinct protein interactions but retain functional redundancy in vivo. Genetics 159: 159-172.

Niu, W., Z. J. Lu, M. Zhong, M. Sarov, J. I. Murray et al., 2011 Diverse transcription factor binding features revealed by genome-wide ChIP-seq in C. elegans. Genome Res 21: 245-254.

Norris, A. D., and E. A. Lundquist, 2011 UNC-6/netrin and its receptors UNC-5 and UNC-40/DCC modulate growth cone protrusion in vivo in C. elegans. Development 138: 4433-4442.

Ohama, Y., and K. Hayashi, 2009 Relocalization of a microtubule-anchoring protein, ninein, from the centrosome to dendrites during differentiation of mouse neurons. Histochem Cell Biol 132: 515-524.

Opperman, K. J., and B. Grill, 2014 RPM-1 is localized to distinct subcellular compartments and regulates axon length in GABAergic motor neurons. Neural Dev 9: 10.

Rawson, J. M., B. Dimitroff, K. G. Johnson, X. Ge, D. Van Vactor et al., 2005 The heparan sulfate proteoglycans Dally-like and Syndecan have distinct functions in axon guidance and visual-system assembly in Drosophila. Curr Biol 15: 833-838.

Rhiner, C., S. Gysi, E. Frohli, M. O. Hengartner and A. Hajnal, 2005 Syndecan regulates cell migration and axon guidance in C. elegans. Development 132: 4621-4633.

Schwabiuk, M., L. Coudiere and D. C. Merz, 2009 SDN-1/syndecan regulates growth factor signaling in distal tip cell migrations in C. elegans. Dev Biol 334: 235-242.

Shen, Y., 2014 Traffic lights for axon growth: proteoglycans and their neuronal receptors. Neural Regen Res 9: 356-361.

Song, S., B. Zhang, H. Sun, X. Li, Y. Xiang et al., 2010 A Wnt-Frz/Ror-Dsh pathway regulates neurite outgrowth in Caenorhabditis elegans. PLoS Genet 6.

Steigemann, P., A. Molitor, S. Fellert, H. Jackle and G. Vorbruggen, 2004 Heparan sulfate proteoglycan syndecan promotes axonal and myotube guidance by slit/robo signaling. Curr Biol 14: 225-230.

Tamayo, J. V., M. Gujar, S. J. Macdonald and E. A. Lundquist, 2013 Functional transcriptomic analysis of the role of MAB-5/Hox in Q neuroblast migration in Caenorhabditis elegans. BMC Genomics 14: 304.

Thakar, S., G. Chenaux and M. Henkemeyer, 2011 Critical roles for EphB and ephrin-B bidirectional signalling in retinocollicular mapping. Nat Commun 2: 431.

Thompson, O., M. Edgley, P. Strasbourger, S. Flibotte, B. Ewing et al., 2013 The million mutation project: a new approach to genetics in Caenorhabditis elegans. Genome Res 23: 1749-1762.

Tulgren, E. D., S. M. Turgeon, K. J. Opperman and B. Grill, 2014 The Nesprin family member ANC-1 regulates synapse formation and axon termination by functioning in a pathway with RPM-1 and beta-Catenin. PLoS Genet 10: e1004481.

Tumova, S., A. Woods and J. R. Couchman, 2000 Heparan sulfate proteoglycans on the cell surface: versatile coordinators of cellular functions. Int J Biochem Cell Biol 32: 269-288.

Wadsworth, W. G., and E. M. Hedgecock, 1996 Hierarchical guidance cues in the developing nervous system of C. elegans. Bioessays 18: 355-362.

Wang, X., J. Liu, Z. Zhu and G. Ou, 2015 The heparan sulfate-modifying enzyme glucuronyl C5-epimerase HSE-5 controls Caenorhabditis elegans Q neuroblast polarization during migration. Dev Biol 399: 306-314.

White, J. G., E. Southgate, J. N. Thomson and S. Brenner, 1986 The structure of the nervous system of the nematode Caenorhabditis elegans. Philos Trans R Soc Lond B Biol Sci 314: 1-340.

Wightman, B., R. Baran and G. Garriga, 1997 Genes that guide growth cones along the C. elegans ventral nerve cord. Development 124: 2571-2580.

Yamaguchi, Y., 2001 Heparan sulfate proteoglycans in the nervous system: their diverse roles in neurogenesis, axon guidance, and synaptogenesis. Semin Cell Dev Biol 12: 99-106.

51 | P a g 
bioRxiv preprint doi: https://doi.org/10.1101/046094; this version posted June 13, 2017. The copyright holder for this preprint (which was not certified by peer review) is the author/funder, who has granted bioRxiv a license to display the preprint in perpetuity. It is made available under aCC-BY-NC-ND 4.0 International license.

Syndecan and Wnt Axon Termination

Zheng, C., M. Diaz-Cuadros and M. Chalfie, 2015a Dishevelled attenuates the repelling activity of Wnt signaling during neurite outgrowth in Caenorhabditis elegans. Proc Natl Acad Sci U S A 112: 13243-13248.

Zheng, C., M. Diaz-Cuadros and M. Chalfie, 2015b Hox Genes Promote Neuronal Subtype Diversification through Posterior Induction in Caenorhabditis elegans. Neuron 88: 514-527.

Zou, Y., 2004 Wnt signaling in axon guidance. Trends Neurosci 27: 528-532.

52 I P a g e 